OECDpublishing

ADDRESSING

SOCIETAL

CHALLENGES USING

TRANSDISCIPLINARY

RESEARCH

OECD SCIENCE, TECHNOLOGY AND INDUSTRY

POLICY PAPERS

June 2020 No. 88 


\title{
ADDRESSING SOCIETAL CHALLENGES USING TRANSDISCIPLINARY RESEARCH
}

\author{
STI POLICY PAPER
}

This paper was approved and declassified by the Committee for Scientific and Technological Policy (CSTP) on 5 June 2020 for publication by the OECD Secretariat.

Note to Delegations:

This document is also available on O.N.E. under the reference code:

DSTI/STP/GSF(2020)4/FINAL

This document, as well as any data and any map included herein, are without prejudice to the status of or sovereignty over any territory, to the delimitation of international frontiers and boundaries and to the name of any territory, city or area.

COECD (2020)

You can copy, download or print OECD content for your own use, and you can include excerpts from OECD publications, databases and multimedia products in your own documents, presentations, blogs, websites and teaching materials, provided that suitable acknowledgment of OECD as source and copyright owner is given. All requests for commercial use and translation rights should be submitted to rights@oecd.org. 


\section{Abstract}

This report looks at how transdisciplinary research, which combines knowledge from different scientific disciplines with that of public and private sector stakeholders and citizens, can be used to address complex societal challenges. This includes developing effective responses in acute crises, such as the COVID-19 pandemic, as well as longer-term solutions for sustainability development. In a series of 28 case studies, each of which is briefly summarised in the report, it identifies the key obstacles to effectively implementing transdisciplinary research. Many of these are embedded in the way that research systems are structured and managed and they are amenable to policy intervention. Examples of how various actors, including funding agencies and universities are adapting to better accommodate the requirements of transdisciplinary research are included in the report and related policy actions are ascribed for these actors. 


\section{Foreword}

Transdisciplinary research (TDR), which involves the integration of knowledge from different science disciplines and (non-academic) stakeholder communities, is required to help address complex societal challenges. However, and despite increasing interest at the policy level, there are significant barriers to conducting rigorous TDR. This report is the output of a project that was commissioned by the OECD Global Science Forum (GSF) and focused on a systematic analysis of methods and practices for TDR at the project level across different communities and countries. It aims to promote mutual learning between countries by:

- reviewing the theoretical foundations and methods of TDR and differentiating it from other related modes of research and broader policy concepts

- developing a standardised analytical framework to explore the key variables and determinants of successful trans-disciplinary research

- using the Framework to analyse case studies of specific initiatives

- analysing relevant information on national policy initiatives to identify good practices

- on the basis of these findings, make a final report and policy recommendations to promote TDR to address complex societal challenges.

An important characteristic of this work is that it takes a holistic approach to analysing the barriers to TDR that takes account of the diversity of drivers, restraints, interests and expectations for different actors.

As this report is being finalised, the Corona Virus Disease (COVID-19) pandemic has been spreading across the World and the full extent of its impacts on human health and the socioeconomic wellbeing are starting to become apparent. Science has been placed at the forefront of the fight against the virus. Scientific data, information and expertise from different domains and different countries is having to be integrated to inform policy makers. Whilst there is hope that effective therapeutics and a vaccine will be quickly developed and tested, it is likely that this will not happen in time to prevent massive socio-economic disruption. In the meantime, difficult choices are having to be made that balance public health and economic imperatives, with implications for all sectors of business and society at different scales from local to global. Trust between science, policy-makers and citizens is critical in making these choices and TDR will be an essential tool for building and maintaining this trust and ensuring the longer-term suitability and effectiveness of mitigation measures. TDR provides a powerful mechanism for combining different branches of knowledge and practice to develop the social and technological solutions that will be required during the extended response and recovery phases of the global response to COVID-19.

A number of the case studies that are included in this report focus on the use of TDR to address complex public health issues or crises. These range from holistic animal and human health management strategies in rural communities in Africa to the use of advanced digital technologies for social and health care in North America. COVID-19 has highlighted the vulnerability of large, densely populated cities and a several case studies focus on health and well-being in complex urban environments. Several studies focus on increasing resilience to longer-term threats, associated with environmental change and there are cases that looks at how TDR can help in dealing with natural disasters. There are lessons to be learned from all of these cases in relation to the COVID-19 pandemic. 
The report is in two main parts that can be read separately: 1 . The overall study review, analysis and recommendations and 2 . The collection of 28 single page vignettes for individual case studies (section 11). Each case study is different and the collection as whole illustrates the diversity of issues that TDR can be used to address and provides some important insights into the practical challenges of bringing together different disciplines and stakeholders to address specific challenges. 


\section{Acknowledgements}

An international Expert Group (annex 1), was established through nominations from GSF delegates, to oversee and implement the project, building on existing work and engaging with relevant stakeholders. The Expert Group was chaired by Jakob Zinsstag (Switzerland) and Tateo Arimoto (Japan). This final policy report is the product of that Group's work. It was drafted by Jose Siri, with input from all Expert Group members and the OECD-GSF Secretariat, Carthage Smith and Yoshiaki Tamura.

In addition to the International Expert Group members, a number of other experts made important contributions. This included the principle investigators or project leaders for the 28 case studies who kindly shared their experience in interviews and provided comments on the draft case vignettes. It includes also more than 100 people who participated in dedicated project workshops that were held in Paris and Tokyo (see annexes 3 and 4) and were generously supported by the host countries.

The Network for Transdisciplinary Research (td-net), which is supported by the Swiss Academies of Arts and Sciences, provided some of the material that is cited in this report and was the main organiser of the International Transdisciplinary Conference in Gothenburg (September 2019). OECD joined with td-net and the International Science Council to organise two sessions at this Conference that enabled discussions with the international community and provided examples of good practice that are included in the report.

The Belmont Forum of research funders, led by US-NSF, organised a workshop on Evaluating Transdisciplinary Approaches in Washington DC (June 2019) that informed the discussions around impact assessment of transdisciplinary research (section 10). 


\section{Table of contents}

Executive Summary $\quad 9$

Recommendations 11

Addressing Societal Challenges Using Transdisciplinary Research 15

1. Background $\quad 15$

2. Transdisciplinarity and related research methods $\quad 16$

3. Methodology and Case Studies 19

4. Rationale for transdisciplinary research $\quad 22$

5. Key parameters of transdisciplinary research projects 24

6. Research system challenges for the effective implementation of transdisciplinarity $\quad 28$

7. Challenges for transdisciplinary research extending beyond research systems 37

8. Monitoring and impact assessment of transdisciplinary projects 39

9. Case study vignettes 40

10. Concluding comments $\quad 69$

$\begin{array}{ll}\text { Notes } & 71\end{array}$

$\begin{array}{ll}\text { References } & 72\end{array}$

$\begin{array}{ll}\text { ANNEXES } & 74\end{array}$

Annex 1. GSF Expert Group Membership $\quad 74$

Annex 2. Case study questionnaire $\quad 75$

Annex 3. Workshop on transdisciplinarity and sustainability research, 24 May 2019, Paris 77

Annex 4. Workshop on Transdisciplinary Research, 5 December 2019, Tokyo 78

$\begin{array}{ll}\text { Glossary } & 79\end{array}$

Tables

Table 1. Case studies

20

Figures

Figure 1. Graphical representation of transdisciplinary research

Figure 2. Conceptual model of a typical interactive and iterative transdisciplinary research project 18

Figure 3. Transdisciplinary research and related modes of research $\quad 19$

Figure 4. TDR project lifecycle, illustrating phasing and depth of participatory engagement 26

Figure 5. Conceptual model of a TDR funding programme $\quad 34$ 


\section{ADDRESSING SOCIETAL CHALLENGES USING TRANSDISCIPLINARY RESEARCH}

\section{Boxes}

Box 1. Messages from case studies: added value of transdisciplinary research 


\section{Executive Summary}

There are a number of societal challenges, often involving complex human-environment systems, that are not fully understood and for which solutions are urgently required. Science has already provided critical insights into the nature, causes and likely trajectory of many of these societal challenges and it is now being called upon to help provide sustainable solutions. The impacts of global warming, biodiversity loss, natural disasters, economic migration and health pandemics are manifest at multiple scales and require both technological and social innovations. In order to achieve this, different scientific disciplines, including natural and social sciences and humanities (SSH) need to work together and to fully engage other public and private sector actors, including policy-makers. Solutions to complex societal challenges, such as those embedded in the Sustainable Development Goals (SDGs), cannot to be generated based solely on disciplinary research but require a paradigm shift in research practice.

Transdisciplinary research (TDR) first emerged as a concept at the OECD International conference on Interdisciplinary Research and Education in 1970. It is a mode of research that integrates both academic researchers from unrelated disciplines - including natural sciences and SSH - and non-academic participants to achieve a common goal, involving the creation of new knowledge and theory. In drawing on the breadth of science and non-scientific knowledge domains such as local and traditional knowledge, and cultural norms and values, it aims to supplement and transform scientific insights for the good of society. It criss-crosses the traditionally separated realms of science and practice and advances both simultaneously.

TDR can address complex problems beyond the reach of traditional science. It offers a practical way to address issues that are highly contested and where stakes are high. It can expand on existing scientific evidence and give rise to more innovative, holistic solutions. It can generate both new scientific insights and practical societal benefits. As such, it is a necessary complement, but not a replacement, to traditional research practices. However, given the scale and urgency of the human-environmental system challenges that society is currently facing, there is a strong argument that TDR needs to be scaled up very considerably and become a mainstream modus operandi for research.

No two TDR research projects are alike but they fit within a broad framework that can be defined by 6 key parameters: the diversity of disciplines engaged; the depth of integration across disciplines; the degree of interaction with non-academic stakeholders; the composition of non-academic stakeholders; the timing of participatory engagement and the types of knowledge that are emphasised. The combination of these parameters is determined by the problem to be addressed and may evolve over time.

Science systems, their institutions, structures and processes, have been largely designed around distinct research disciplines and this presents a number of significant barriers to the promotion of TDR. Academic and professional training is normally organised in disciplines and not easily adapted to accommodate students who wish to engage in TDR. Peer-review, evaluation and promotion processes are likewise normally organized in disciplines and the key performance measures are based on scientific publications and citations, rather than societal benefits that are the main aim of TDR research. Funding allocation mechanisms, are mainly targeted at research excellence, which again is largely assessed in terms of scientific publication outputs. Excellence and rigor are equally important for TDR but there is a need to re-define how we evaluate and measure these qualities. 
Across the world, Universities and public research institutions are beginning to recognise the importance of trans-disciplinary research, not only in terms of generating new scientific knowledge/research excellence but also as a mechanism to link their research mission with their so-called $3^{\text {rd }}$ mission to promote innovation and societal benefit. A small number of Universities have gone as far as articulating their missions and reorganising their faculty and departmental structures around societal challenges. Others have invested in interdisciplinary and/or multi-stakeholder platforms and recruited new expertise in TDR and some have adjusted their teaching and training activities to promote TDR. In some countries, public research institutions have been established in domains such as sustainability science or disaster research that are inherently trans-disciplinary. And new institutional networks are being established at a number of scales, from local to global, engaging different types of public and private institutions, including for example research universities and universities/institutes of applied science.

Research funders are also innovating in response to the challenges that arise in supporting TDR. Some countries are re-focusing their STI strategies around the SDGs and/or societal challenges. Dedicated challenge-driven research funding schemes have been implemented in many countries and some of these mandate TDR approaches. Peer review and programme development and management processes have been adapted to take account of the specificities of TDR and different donors are working together, and in some cases pooling resources across borders, to support TDR that addresses shared societal challenges.

Looking beyond research systems there are two inter-related challenges for conducting TDR: 1 . How to select and effectively engage non-academic stakeholders, and 2 . The ethical considerations that often arise from this engagement. These are not issues that researchers from many disciplines are normally confronted with. Again, for these issues to be addressed effectively in the longer term, both research funders and institutions need to implement structures and or mechanisms to support researchers in dealing with them.

A major basis for the analysis in the current report was 28 de novo case studies of individual TDR projects. These cover a broad range of fields, geographic areas, scales, disciplines and stakeholders. Each project is unique but the overall collection of case vignettes, which are included in the second part of this report, illustrates the variety and importance of scientific and societal issues that require a TDR approach. Each vignette includes a summary of the experiences from an individual project in terms of lessons learnt and policy implications. In addition, a more normative analysis of all these cases, based on detailed case interviews has been carried out. The recommendations that result from this analysis are listed in the following section. 


\section{Recommendations}

A number of issues emerging from this work-including the case study analysis - merit consideration by policy makers and other actors with a shared interest in how science can effectively support solutions for complex societal challenges. TDR is required to address such challenges but significant obstacles limit implementation of TDR at the necessary scale. Many of these obstacles are embedded in the traditional disciplinary structures, norms and practices of our science systems but are amenable to judicious policy intervention. Governments, research agencies, research institutions and international bodies all have a role to play in designing and implementing effective policy initiatives. As highlighted in this report, there are many good practices to build on. Mutual learning, collaboration, and exchange are required at the policy level as well as at the practitioner level.

\section{Governments}

Governments need to recognise and promote transdisciplinary research, as an essential complement to other more traditional research approaches, in addressing complex societal challenges. Governments have a critical role to play in establishing the overall framework that enables and supports effective TDR. This includes:

1. Providing dedicated and sustainable resources for TDR, in particular in relation to STI for societal challenges and the Sustainable Development Goals;

2. Facilitating and supporting the engagement of public sector actors - including policy makers - in TDR activities and making the relevant public sector data available for use in these activities;

3. Incentivising other actors, including from the private sector, to support and participate in TDR to address societal challenges;

4. Promoting cooperation across ministries and responsible public authorities, including pooling of resources where appropriate, e.g. for research, innovation and overseas development, for TDR that addresses complex societal challenges.

\section{Research Funders}

Research funding agencies have a critical role to play by directly supporting and incentivising TDR research. This affects both prioritisation of research areas and changes to funding processes, including funding criteria, peer review and evaluation. Specific actions that can be taken by funders include:

1. provision of dedicated, long-term funding for TDR to address societal challenges, e.g. challenge-based funding, at local, national and international scales

2. support to establish centres of expertise and national and international networks in inter- and trans-disciplinary research domains

3. experimentation with different mechanisms to support the development of rigorous TDR projects, including sand-pit processes and training workshops for researchers

4. implementation of proactive management and monitoring of TDR programmes, recognising that flexibility is required to accommodate the evolving goals that are inherent in TDR projects. The management overhead, at both project and programme level, is likely be higher than for more traditional research 
5. changes to peer review and evaluation processes, including the use of multi-disciplinary and multi-stakeholder review processes and selection of peer-reviewers with prior experience in doing TDR

6. emphasising the evaluation of societal as well as scientific outputs and impacts in both ex ante and ex poste assessment of projects

7. extension of funding, and/or collaboration with other donors, to support capacity building and the participation of non-academic stakeholders in TDR projects

8. individual support, e.g. Fellowships, for outstanding individuals, who can develop and lead TDR projects.

\section{Universities and Public Research Institutions (PRIs)}

Universities and PRIs are the principle organisations through which TDR is carried out and their long-term strategic commitment and support is essential if TDR is to be expanded to the scale that is necessary to address complex societal challenges. This has implications for education and training, as well as research. It also cuts across the so-called 3rd mission activities (societal engagement and innovation) of universities and PRIs. Specific actions that can be taken by universities and PRIs include:

1. introduction of challenge-based approaches in research strategies and organisational structures

2. development of sustainable institutional structures and mechanisms (e.g., cross-department committees and meetings, shared infrastructure, flexible schedules, pump-priming funds) to foster cooperation across disciplines and to support TDR

3. establishment of structures and mechanisms to build long-term trusted relations with external stakeholder communities, including creation of formal, high-profile interfaces with civil society and private and public sector entities

4. allocation of core resources, including personnel, to build long-term expertise in TDR methodologies and practice

5. introduction of TDR learning modules into science education and postgraduate training courses;

6. support for early career researchers to engage in TDR projects, e.g. jointly supervised PhDs, and development of more flexible career paths

7. changes to evaluation and promotion criteria for individuals who engage in TDR, so that they are judged not only on scientific publications and citations but also on their contribution to collective research outputs that are of value to stakeholders outside of science

8. establishment of local, national and international networks of institutions that cooperate and exchange best practices in relation to TDR. These might be focused on local challenges, selected domains, such as sustainability research or global health, or more generic aspects of TDR.

\section{The academic community and science associations}

The academic community has a major influence on science policy development and the definition of research strategies and priorities. It is responsible for conducting peer review and evaluation processes and often has a strong voice in how these are designed and conducted. Universities and PRIs tend to have considerable autonomy and are rightly 
responsive to their academic employees. Thus, whilst policy-makers and other actors can provide mandates and incentives for TDR, their impact will be limited without the support of the academic community and its representative associations. Key actions that can be taken by the academic community include:

1. development and recognition of new inter-and trans-disciplinary research fields, such as sustainability research and planetary health, including the promotion of relevant scientific journals

2. support for, and participation in, new research management approaches, including innovative peer review and evaluation processes, that would promote TDR

3. support, including mentorship, for early career researchers who wish to engage in TDR

4. development of strategies and assessments, e.g. by National Academies or international science bodies, of the needs and potential for TDR to address societal challenges

5. development of international frameworks or programmes for TDR that addresses complex societal challenges

6. contributing to the development of new STI indicators and measures that value the combination of multiple research outputs.

\section{Intergovernmental Organisations}

One of the major policy drivers for more TDR is the UN Sustainable Development Goals. Inherent in these goals is the recognition that no single country can fully address them on its own and there is a need for more effective international cooperation and exchange. Whilst the UN and other international bodies, including the OECD do not have the resources or the authority to implement TDR at the scale required to address societal challenges, these international bodies can play an important role in building consensus and catalysing action. Specific roles that international bodies can play include:

1. building awareness of TDR into existing policy frameworks (e.g. the SDGs or Responsible Research Innovation);

2. fostering capacity-building, e.g. by convening meetings of development donors and research funders;

3. promulgating guidelines/best practices/case studies of TDR;

4. promoting international alliances/networks and forums that bring together scientists and other stakeholders.

In addition to these 5 groups of actors, who have the major responsibility for promoting and enabling TDR within scientific research systems, there are a number of other stakeholders that need to embrace TDR if we are to effectively address that complex challenges that society is currently confronted with. Principle among these are many actors from the private sector and civic society/NGOs. Both of these are very heterogeneous groupings with conflicting interests but it is reasonable to assume that the majority of their members have a stake in finding solutions to the societal challenges with which we are all confronted.

The private sector has enormous intellectual, technological and financial resources as well as valuable data and information, all of which can be leveraged in TDR. As illustrated by many of the cases in the current report, engagement in TDR can provide a variety of significant benefits for private firms that range from a better understanding of potential 
markets and longer-term drivers through to improved technological development and innovation. Whilst intellectual property protection and confidentiality concerns can be an obstacle to engagement with academia and other stakeholders, where these can be overcome the mutual benefit that arises from engagement in TDR projects can be considerable.

Non-governmental organisations (NGOs) represent different societal interests and as such they can make a very valuable contribution to many TDR activities. In addition to knowledge and expertise they can sometimes act as a proxy, and/or provide a mechanism, for engagement of important citizen groupings including neglected communities. On many complex societal issues, NGOs are at the forefront of public debates and are both producers and users of knowledge. As with the private sector (and indeed the science sector) there are lines that need to be respected between research and advocacy but provided that these are openly recognised and respected, the mutual benefit of engaging NGOs in TDR can be very considerable.

Many private sector actors and NGOs have experience of working together in TDR projects and there is an urgent need to build on these experiences and provide incentives and, where necessary, support for multi-stakeholder engagement in addressing shared societal challenges using TDR. 


\section{Addressing Societal Challenges Using Transdisciplinary Research}

\section{Background}

Transdisciplinarity (TD) is defined by the integration of academic researchers from different disciplines with non-academic participants in co-creating new knowledge and theory to achieve a common goal (Swiss Academies of arts and sciences, n.d.[1]).As such, TDR is increasingly cited as a means for addressing complex societal challenges, such as those encompassed by the United Nations Sustainable Development Goals (SDGs). ${ }^{1}$ In part, this growing awareness rests on a recognition of the importance of coupled humanenvironment systems (HES) at multiple scales and their implications for society. Causal pathways in such systems transcend disciplines or sectors and are highly context dependent. Addressing their manifold consequences requires thinking and acting beyond the traditional bounds of individual scientific disciplines, and indeed beyond the scientific enterprise itself, to other relevant stakeholder domains. It calls for better integration between natural sciences and social sciences and humanities ( $\mathrm{SSH}$ ), a more direct relationship between science and society, and the inclusion of non-scientific stakeholders in research processes at all stages (see Figure 1 and Glossary).

Figure 1. Graphical representation of transdisciplinary research

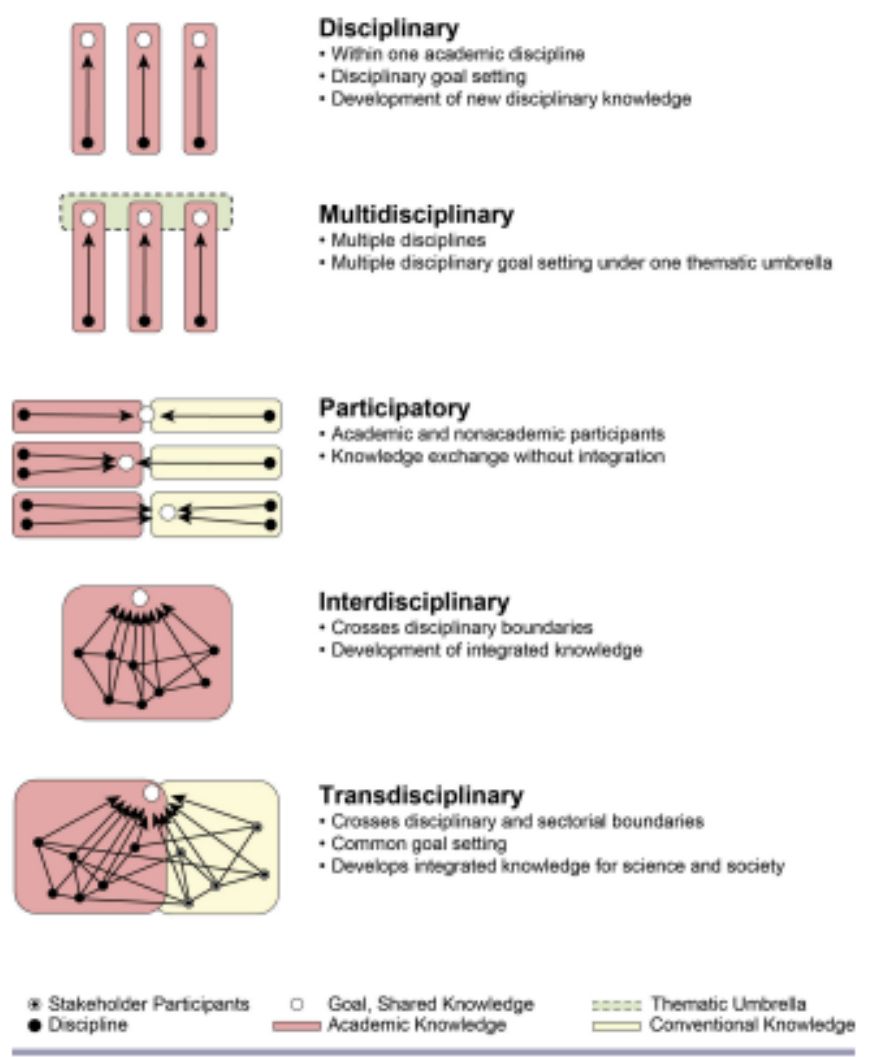

Source: Architectures of adaptive integration in large collaborative projects (Wright Morton, Eigenbrode and Martin, 2015[2]) 
Under conventional research approaches, societal problems are identified, and solutions are planned, developed and evaluated, by experts - scientists, in the context of research processes - and then applied to target populations. Transdisciplinary approaches, in contrast, use participatory engagement to involve target populations, relevant authorities, and other actors, aiming to understand their perceptions, expectations and priorities, and to make effective use of their experiential and contextual knowledge. As expressed by Hirsch Hadorn et al. $\left(2008_{[3]}\right)$, "through scientists entering into dialogue and mutual learning with societal stakeholders, science becomes part of societal processes, contributing explicit and negotiable values and norms in society and science, and attributing meaning to knowledge for societal problem-solving."

In practice, there are significant obstacles to getting different disciplines to come together to conduct interdisciplinary research (Van Noorden, 2015 [4] $)$, and implementation of TDR is even more challenging. If the latter is to evolve from a marginal theoretical concept into a mainstream approach, important questions must be resolved, including about methods and practice, institutions and environments, research support, publication and impact, education and training, data integration and the coordination of global research to address societal challenges.

Further questions involve how to evaluate TDR before, during and after the fact. In particular, the science and policy communities need criteria to assess whether TDR proposals are likely to yield desired results, indicators to weigh the progress and sustainability of existing research efforts and ensure continued application of the principles of TD, and standards - practical, scientific, and ethical-for appraising the value of completed research.

This document begins with a brief history of TDR and how it relates to other terms that are commonly used in Science, Technology and Innovation (STI) policy. It follows with an introduction to a set of case studies, which help to illustrate a discussion on criteria forand the added value of-adopting TDR approaches. The key parameters that define TDR projects are then described, followed by an analysis of how these are reflected at the practical project level. The main structural challenges to promoting TDR are analysed, and examples of what different actors, including funders and Universities/research institutions, are doing to address them are presented. Dedicated sections are devoted to monitoring and evaluation and the broader issues relating to science and society, which have particular importance for science policy. Then, in part 2 of the report, each of the 28 de novo case studies that provide the basis of the cross-cutting analysis is briefly summarized. Both the more normative cross-cutting analysis and the individual case studies feed into a set of policy recommendations/options that are laid out at the start of this report (see previous section) and summarised at the end in short concluding comments. These recommendations are addressed to different groups of actors, all of whom need to work together to promote TDR to address socio-economic and scientific challenges.

\section{Transdisciplinarity and related research methods}

\subsection{Historical development}

While a full treatment of the history of TD and related concepts is beyond the scope of this report, a few key points are summarised here (Zinsstag et al., 2015 ${ }_{[5]}$ ). Modern science emerged in the scientific revolution of the $16^{\text {th }}$ and $17^{\text {th }}$ centuries. While drawing on concepts from antiquity, it diverged from traditional philosophy in its reliance on controlled experimental research to elucidate empirical laws, complementing, if not superseding, the long-established focus on deductive reasoning from first principles (Hadorn et al., 2008 ${ }_{[3]}$ ). While, from its inception, natural science had strong linkages with technological innovation 
for economic and societal gain, its focus on empiricism through experimentation tended toward an increasing dissociation from practical, lived experience. ${ }^{2}$

The $19^{\text {th }}$ and early $20^{\text {th }}$ centuries featured the separation of the traditional humanities from philosophy, and later the development and formalisation of the social sciences. These fields applied scientific reasoning to elucidate universal laws governing human experience, yet also recognized the limitations of generalized interpretation: "the natural sciences explain general aspects of empirical events by universal laws, while history investigates the individuality of empirical phenomena, giving them values to aid the understanding of their meaning and importance." 3 SSH emerged in part from a recognition of science's potential contribution to understanding and addressing social challenges. Indeed, practical problems in society, such as poverty, were explicitly recognised as a stimulus for scientific research, paralleling the application of natural science to practical problems in technology. Yet, the focus of SSH on meaning, interpretation, norms, values, and context contrasted with the natural science emphasis on explanation in neutral, universal, idealised terms.

With the burgeoning corpus of scientific knowledge, there was fragmentation and specialisation of scientific disciplines in virtually all domains. One consequence of this was the recognition that complex, emerging phenomena could not be understood or addressed from within knowledge and practice siloes. In response, systems theory was developed along parallel lines by practitioners in a broad range of fields, including biology, cybernetics, game theory, information theory, and sociology. Beginning in the 1940s, systems theory examined "the abstract organisation of phenomena, independent of their substance, type, or spatial or temporal scale of existence ... [It gave] rise to the idea of an abstract structural unity of scientific knowledge against the background of... progressive fragmentation... (Jantsch, 1972[6])." This idea constituted a powerful argument for integrative research that could bridge silos and address complexity. The term "transdisciplinarity" was first introduced 50 years ago, at the OECD International conference on Interdisciplinary Research and Education, in the context of a call for valuesdriven innovation for society, coordinated within the triad of government-industryuniversity (Jantsch, 1972[6]).

While science remains dominated by traditional disciplinary structures, the concept of transdisciplinary systems thinking has been highly influential, leading to a proliferation of related methodological approaches over the past half-century. Beyond TDR itself, these include: operations research; systems approaches; action research; place-based research; team science; integration and implementation science; ethical, legal and social implications research; citizen science, convergence research, and post-normal or mode 2 science. The innovation community - the modern instantiation of the long-standing partnership between science and technology - embraces related frameworks, including responsible research and innovation; open innovation and social innovation. Each of these varied methods has different aims and focus (see Figure 2), but they share broadly similar fundamental assumptions, including about the validity of different knowledge sources, the importance of complexity, and the need to engage with the knowledge and values of relevant stakeholders.

Such approaches have become particularly important in the context of sustainable development. The Brundtland Report from the United Nations World Commission on Environment and Development $\left(1^{1987_{[7]}}\right.$ ), the United Nations Conference on Environment and Development in Rio de Janeiro (1992), and the United Nations Sustainable Development Goals (2015) offer progressively stronger assertions of the need for systemic, integrated approaches and inclusive participation to address conjoined development issues. In 2012, the 'Future Earth' initiative of the International Science Council was launched at the UN Conference on Sustainable Development. This aims to bring together scientists 
from different domains of global change research to work with other stakeholders to address global sustainability challenges.

The theoretical and conceptual thinking that underpins TDR is in itself an active area of scientific development and there are many different models that try and capture the essence of what it is and how it really represent a paradigm shift in research practice that can be applied to address complex or 'wicked' problems. One of the key defining features is that it criss-crosses the traditionally separated realms of science and practice as illustrated in Figure 2.

Figure 2. Conceptual model of a typical interactive and iterative transdisciplinary research project

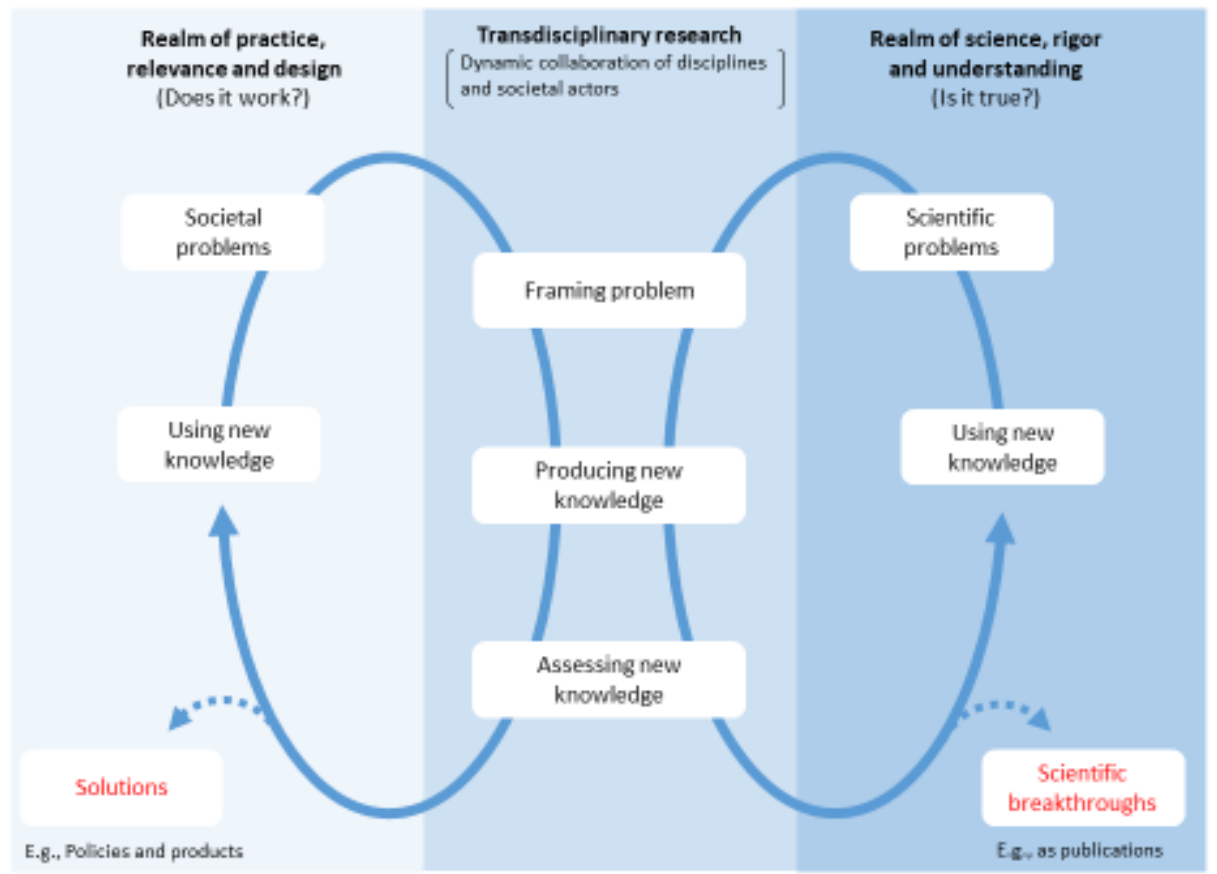

Source: authors' design based on Gredig (2011 [8] $)$, Jahn et al (2012[9]), Lang et al (2012[10]), Pohl et al (2017[11]).

\subsection{Relation between TDR and other related concepts}

TDR features both interdisciplinarity and co-creation (i.e., co-design of research and co-production of knowledge) with actors outside of academia. As introduced in the previous section, several related modes of research overlap with TDR but do not necessarily incorporate both interdisciplinarity and co-creation (see Figure 3). Thus, team science and convergence research are characterised by the integration of different disciplines, whereas action research/operational research and development research very often involve co-creation. Citizen science can be defined more or less broadly but does not necessarily involve either interdisciplinarity or co-creation. Different communities identify with these semi-discrete modes of research, which have developed their own distinct frameworks and terminology. 
Figure 3. Transdisciplinary research and related modes of research

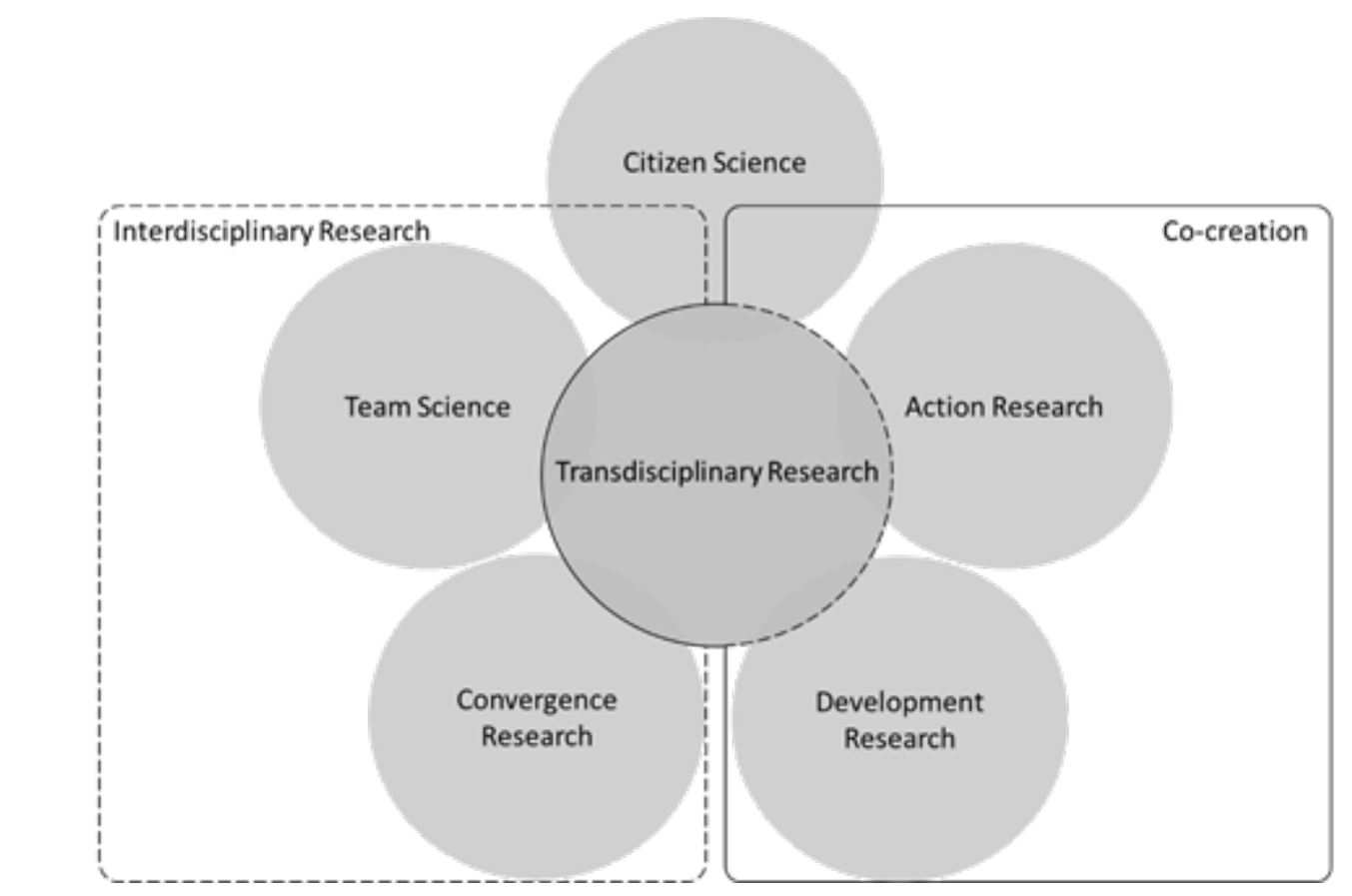

Source: authors' original design.

There are also a number of other umbrella concepts that are used in the science and innovation policy community and imply a need for more TDR. Hence, TDR is compatible with Open Science with its emphasis on societal engagement and with Responsible Research and Innovation (or Open Innovation) and its emphasis on multi-stakeholder engagement. Likewise, Mission-driven Research and Innovation will often require TDR approaches. This is implicit also in discussions around Post-normal science, with its emphasis on uncertainty and complexity. Relative to these broader concepts, TDR can be considered as a potential delivery mechanism, i.e. it is a mode of research that can help to deliver particular aims and address societal challenges and, as such, it is a complement to other research and innovation approaches or activities.

The overlap between different terminology and concepts, can be a significant obstacle to effective communication and collaboration across different communities. Indeed, TDR itself is sometimes mistakenly identified as being exclusive to social sciences and so disregarded as a potential approach by those coming from other domains. Despite the confusion inherent in having overlapping concepts and modes of research, trying to clearly demarcate between different 'schools of thought' has diminishing returns and what is more important is to recognise the complementarities and focus on the potential for mutual learning across different communities. Adopting the best approach for the research challenge in hand is more important than the label that is attached to that approach.

\section{Methodology and Case Studies}

This report combines information from various sources, including the knowledge of individual experts (annex 1), published literature, two dedicated workshops in Paris (May 2019) and Tokyo (December 2019), and sessions on funding and research institutions at the International Transdisciplinarity Conference, Gothenburg (September 2019). Policy initiatives to support TDR from the OECD-STIP compass database (EC/OECD, 2020 $\left.0_{[12]}\right)$ have been analysed, and examples of good practices have been identified by the 
international Expert Group (EG) established to oversee the work. All these inputs complement 28 de novo project case studies that were conducted specifically for this project.

The case studies cover a broad range of fields, geographic areas, scales (local to international), disciplines and stakeholders, proposed and selected by EG members in line with a robust definition of TDR, ${ }^{4}$ Principal investigator(s) for each case study were sent an online questionnaire (see annex 2) and then interviewed by an EG member. Interviews focused on challenges and lessons learned/good practices. The written record of these interviews was the basis of the analysis in this report.

The case studies and their main features are described in Table 1 below and a 1-page summary of each is provided in section 11 . Each project is unique, but the overall collection of case vignettes illustrates the variety and importance of scientific and societal issues requiring a TDR approach, as discussed in the following section.

\section{Table 1. Case studies}

\begin{tabular}{|c|c|c|c|c|c|}
\hline Project Name (acronym) & Subject Area & Involved Discipline & $\begin{array}{l}\text { Lead } \\
\text { Country } \\
\text { (scale) }\end{array}$ & Stakeholder & $\begin{array}{l}\text { Years of } \\
\text { Operation }\end{array}$ \\
\hline Acclimaterra & Climate change & $\begin{array}{l}\text { Climate sciences, agriculture, } \\
\text { hydrology, biodiversity, } \\
\text { history, sociology }\end{array}$ & $\begin{array}{l}\text { France } \\
\text { (Local) }\end{array}$ & $\begin{array}{l}\text { Municipalities, public } \\
\text { institutions, NGOs and } \\
\text { citizens }\end{array}$ & $2013-2019$ \\
\hline $\begin{array}{l}\text { Agrophotovoltaics - } \\
\text { Resource-Efficient Land } \\
\text { Use } \\
\text { (APV-RESOLA) }\end{array}$ & $\begin{array}{l}\text { Solar energy-food } \\
\text { nexus }\end{array}$ & $\begin{array}{l}\text { Technology, environment and } \\
\text { biodiversity, energy economy, } \\
\text { agriculture, society and } \\
\text { politics }\end{array}$ & $\begin{array}{l}\text { Germany } \\
\text { (Local) }\end{array}$ & $\begin{array}{l}\text { Farmer, renewable energy } \\
\text { and grid companies, local } \\
\text { government, politicians, } \\
\text { NGO and citizens }\end{array}$ & $2015-2019$ \\
\hline $\begin{array}{l}\text { ASU Decision Centre for } \\
\text { a Desert City } \\
\text { (DCDC) }\end{array}$ & Water resource & $\begin{array}{l}\text { Decision science, policy } \\
\text { science, geography, } \\
\text { hydrology, life science, } \\
\text { economics, anthropology, } \\
\text { computer science, urban } \\
\text { planning and public } \\
\text { administration }\end{array}$ & $\begin{array}{l}\text { USA } \\
\text { (Local) }\end{array}$ & $\begin{array}{l}\text { Local government and } \\
\text { environmental organization }\end{array}$ & $2004-$ \\
\hline CAMINOLARGO & Traditional music & Music, art and law & $\begin{array}{l}\text { Colombia } \\
\text { (national) }\end{array}$ & $\begin{array}{l}\text { Musician, dancer and } \\
\text { teacher }\end{array}$ & $2017-2019$ \\
\hline $\begin{array}{l}\text { Climate Change and Sea } \\
\text { Level Rise in the } \\
\text { Anthropocene }\end{array}$ & Climate change & $\begin{array}{l}\text { Law, international law and } \\
\text { Geology/Earth sciences }\end{array}$ & $\begin{array}{l}\text { Norway } \\
\text { (International) }\end{array}$ & $\begin{array}{l}\text { International association, } \\
\text { media, filmmakers, artists, } \\
\text { cultural organisations, etc. }\end{array}$ & $2014-2019$ \\
\hline $\begin{array}{l}\text { The Centre for Research- } \\
\text { based Innovation in } \\
\text { Sustainable fish capture } \\
\text { and Processing } \\
\text { technology (CRISP) }\end{array}$ & $\begin{array}{l}\text { Sustainable fish } \\
\text { industry }\end{array}$ & $\begin{array}{l}\text { Fish finding, catch } \\
\text { identification, fishing gear } \\
\text { control and quality } \\
\text { improvement }\end{array}$ & $\begin{array}{l}\text { Norway } \\
\text { (National) }\end{array}$ & $\begin{array}{l}\text { Manufacturers of fishing } \\
\text { equipment, fishermen's } \\
\text { association, etc. }\end{array}$ & $2011-2019$ \\
\hline CuveWaters & $\begin{array}{l}\text { Water resource } \\
\text { management }\end{array}$ & $\begin{array}{l}\text { Social science, civil } \\
\text { engineering Urban water } \\
\text { management, }\end{array}$ & $\begin{array}{l}\text { Germany } \\
\text { (International) }\end{array}$ & $\begin{array}{l}\text { Water reclamation } \\
\text { company, ministries, } \\
\text { regional and local } \\
\text { authorities and leaders, } \\
\text { citizens and NGO }\end{array}$ & $2006-2015$ \\
\hline Food4Sustainability & Food & $\begin{array}{l}\text { Economics, policy science, } \\
\text { business, philosophy, } \\
\text { psychology, agronomy, SSH }\end{array}$ & $\begin{array}{l}\text { Belgium } \\
\text { (local) }\end{array}$ & $\begin{array}{l}\text { Supermarket, local } \\
\text { producer and the Belgian } \\
\text { government }\end{array}$ & $2014-2018$ \\
\hline $\begin{array}{l}\text { Frugal Innovations and } \\
\text { Responsible } \\
\text { Entrepreneurship }\end{array}$ & Water and health & $\begin{array}{l}\text { Technology, medical } \\
\text { anthropology and ethics }\end{array}$ & $\begin{array}{l}\text { Netherlands } \\
\text { (International) }\end{array}$ & $\begin{array}{l}\text { Electronics company, water } \\
\text { company and NGO }\end{array}$ & $2015-2019$ \\
\hline
\end{tabular}




\begin{tabular}{|c|c|c|c|c|c|}
\hline Project Name (acronym) & Subject Area & Involved Discipline & $\begin{array}{l}\text { Lead } \\
\text { Country } \\
\text { (scale) }\end{array}$ & Stakeholder & $\begin{array}{l}\text { Years of } \\
\text { Operation }\end{array}$ \\
\hline $\begin{array}{l}\text { Governing risk society } \\
\text { (GOVRISK) }\end{array}$ & $\begin{array}{l}\text { Flood, landslide } \\
\text { and climate } \\
\text { change }\end{array}$ & $\begin{array}{l}\text { Environmental science, } \\
\text { geoscience and ecology, } \\
\text { political science and law }\end{array}$ & $\begin{array}{l}\text { Norway } \\
\text { (International) }\end{array}$ & $\begin{array}{l}\text { Private company and the } \\
\text { Norwegian government }\end{array}$ & $2014-2018$ \\
\hline $\begin{array}{l}\text { Strengthening } \\
\text { international } \\
\text { Collaboration for } \\
\text { Capitalising on Cost- } \\
\text { effective and Life-saving } \\
\text { Commodities } \\
\text { (i4C) }\end{array}$ & Public health & $\begin{array}{l}\text { Art, political science, } \\
\text { interdisciplinary humanities } \\
\text { and medicine }\end{array}$ & $\begin{array}{l}\text { Norway } \\
\text { (International) }\end{array}$ & $\begin{array}{l}\text { International organization, } \\
\text { the Namibian government, } \\
\text { etc. }\end{array}$ & $2014-2019$ \\
\hline $\begin{array}{l}\text { Innovating Spatial } \\
\text { Development Planning by } \\
\text { Differentiating Land } \\
\text { Ownership and } \\
\text { Governance } \\
\text { (INDIGO) }\end{array}$ & Land use & $\begin{array}{l}\text { Spatial planning, territorial } \\
\text { development, geography, } \\
\text { legal studies, environmental } \\
\text { sociology and political } \\
\text { economy }\end{array}$ & $\begin{array}{l}\text { Belgium } \\
\text { (International) }\end{array}$ & $\begin{array}{l}\text { Consulting offices in spatial } \\
\text { planning; government } \\
\text { agencies in planning, } \\
\text { environment, rural } \\
\text { development; landowners; } \\
\text { professional federations of } \\
\text { planners and notaries; } \\
\text { nature conservation } \\
\text { organisations; farmers; } \\
\text { housing providers }\end{array}$ & $2015-2018$ \\
\hline $\begin{array}{l}\text { International Research } \\
\text { Institute of Disaster } \\
\text { Science } \\
\text { (IRIDeS) }\end{array}$ & Natural disaster & $\begin{array}{l}\text { Engineering, physics, } \\
\text { medicine and history }\end{array}$ & $\begin{array}{l}\text { Japan } \\
\text { (national) }\end{array}$ & $\begin{array}{l}\text { Local government, IT } \\
\text { company and citizens }\end{array}$ & $2012-$ \\
\hline $\begin{array}{l}\text { Japan-ASEAN Science, } \\
\text { Technology and } \\
\text { Innovation Platform } \\
\text { (CHIRP/JASTIP)/ } \\
\text { Collaboration Hubs for } \\
\text { international research } \\
\text { programme }\end{array}$ & $\begin{array}{l}\text { Energy, } \\
\text { bioresources and } \\
\text { disaster }\end{array}$ & $\begin{array}{l}\text { Energy and material } \\
\text { sciences, forestry, } \\
\text { biotechnology, natural } \\
\text { disaster-related sciences, } \\
\text { anthropology, humanities and } \\
\text { social science }\end{array}$ & $\begin{array}{l}\text { Japan } \\
\text { (International) }\end{array}$ & $\begin{array}{l}\text { Inter-governmental } \\
\text { organisation, national and } \\
\text { local government, private } \\
\text { sector and civil society }\end{array}$ & $\begin{array}{c}2015-2020(\max . \\
\text { extension 2025) }\end{array}$ \\
\hline $\begin{array}{l}\text { Jigjiga University One } \\
\text { Health Initiative } \\
\text { (JOHI) }\end{array}$ & Public health & $\begin{array}{l}\text { Human health, veterinary } \\
\text { medicine, nutrition, water and } \\
\text { sanitation and rangeland } \\
\text { management }\end{array}$ & $\begin{array}{l}\text { Switzerland } \\
\text { (International) }\end{array}$ & $\begin{array}{l}\text { Pastoralist and agro- } \\
\text { pastoralist community, } \\
\text { health and animal health } \\
\text { care provider, and regional } \\
\text { and federal authority }\end{array}$ & $2015-2025$ \\
\hline $\begin{array}{l}\text { Lively Agricultural } \\
\text { Landscapes }\end{array}$ & Agriculture & $\begin{array}{l}\text { Agriculture science, social } \\
\text { science, environmental } \\
\text { science. ecosystem services }\end{array}$ & $\begin{array}{l}\text { Germany } \\
\text { (Local) }\end{array}$ & $\begin{array}{l}\text { Farmers, winegrower and } \\
\text { local authorities }\end{array}$ & $2014-2021$ \\
\hline MobilAir & $\begin{array}{l}\text { Transport, } \\
\text { atmospheric } \\
\text { pollution and } \\
\text { health }\end{array}$ & $\begin{array}{l}\text { Environmental economics, } \\
\text { sociology, geography, } \\
\text { behavioural psychology, } \\
\text { biology and health sciences }\end{array}$ & $\begin{array}{l}\text { France } \\
\text { (Local) }\end{array}$ & $\begin{array}{l}\text { Ministry of Research, local } \\
\text { authorities and citizens }\end{array}$ & $2018-2021$ \\
\hline $\begin{array}{l}\text { Mobility Innovation } \\
\text { Center by COI (Mobility) }\end{array}$ & Mobility & $\begin{array}{l}\text { Engineering, human health, } \\
\text { sociopsychology and law }\end{array}$ & $\begin{array}{l}\text { Japan } \\
\text { (Local) }\end{array}$ & $\begin{array}{l}\text { Car manufacturing } \\
\text { company, local government } \\
\text { and citizens }\end{array}$ & $2013-2021$ \\
\hline MONTANAQUA & $\begin{array}{l}\text { Water } \\
\text { management }\end{array}$ & $\begin{array}{l}\text { Geography, environmental } \\
\text { sciences and social science }\end{array}$ & $\begin{array}{l}\text { Switzerland } \\
\text { (Local) }\end{array}$ & $\begin{array}{l}\text { Representatives of } \\
\text { hydropower, viticulture, } \\
\text { agriculture, tourism, } \\
\text { environment, communes } \\
\text { and canton }\end{array}$ & $2010-2013$ \\
\hline $\begin{array}{l}\text { Participatory Value } \\
\text { Evaluation of energy } \\
\text { policies }\end{array}$ & CO2 emission & $\begin{array}{l}\text { Energy system, behavioral } \\
\text { econometrics and ethics }\end{array}$ & $\begin{array}{l}\text { Netherlands } \\
\text { (National) }\end{array}$ & Energy consulting company & $2018-2021$ \\
\hline $\begin{array}{l}\text { Precise Advanced } \\
\text { Technologies and Health } \\
\text { Systems for Underserved } \\
\text { Populations } \\
\text { (PATHS-UP) }\end{array}$ & Health & $\begin{array}{l}\text { Biomedical, electrical } \\
\text { mechanical and industrial } \\
\text { engineering, computer } \\
\text { science, chemistry, material, } \\
\text { medicine, community }\end{array}$ & $\begin{array}{l}\text { USA } \\
\text { (Local) }\end{array}$ & $\begin{array}{l}\text { Patient, health care } \\
\text { provider, caregiver, } \\
\text { community health } \\
\text { advocate, industry, } \\
\text { insurance provider, private }\end{array}$ & $2017-$ \\
\hline
\end{tabular}




\begin{tabular}{|c|c|c|c|c|c|}
\hline Project Name (acronym) & Subject Area & Involved Discipline & $\begin{array}{l}\text { Lead } \\
\text { Country } \\
\text { (scale) }\end{array}$ & Stakeholder & $\begin{array}{l}\text { Years of } \\
\text { Operation }\end{array}$ \\
\hline & & $\begin{array}{l}\text { engagement and behavioural } \\
\text { psychology }\end{array}$ & & $\begin{array}{l}\text { foundation and government } \\
\text { agency }\end{array}$ & \\
\hline PigSustain & Pig industry & $\begin{array}{l}\text { Animal science, } \\
\text { environmental science, public } \\
\text { health, risk assessment, } \\
\text { human geography, IT and } \\
\text { agricultural economics }\end{array}$ & $\begin{array}{l}\text { UK } \\
\text { (National) }\end{array}$ & $\begin{array}{l}\text { Pig producers, retailers, } \\
\text { NGOs, vets and UK } \\
\text { government }\end{array}$ & $2017-2021$ \\
\hline $\begin{array}{l}\text { Sociotechnical Systems } \\
\text { to Enable Smart and } \\
\text { Connected Energy-Aware } \\
\text { Residential Communities } \\
\text { (SSC-IRG) }\end{array}$ & Energy & $\begin{array}{l}\text { Civil/mechanical engineering } \\
\text { and political science }\end{array}$ & $\begin{array}{l}\text { USA } \\
\text { (Local) }\end{array}$ & $\begin{array}{l}\text { Local government and } \\
\text { housing developers }\end{array}$ & $2015-$ \\
\hline $\begin{array}{l}\text { Smart community } \\
\text { policing }\end{array}$ & Policing system & $\begin{array}{l}\text { Virtual Reality(VR), robotics, } \\
\text { Big Data, material sciences, } \\
\text { Al, police study, forensic } \\
\text { science and law }\end{array}$ & $\begin{array}{l}\text { Korea } \\
\text { (National) }\end{array}$ & The Korean government & $2018-2025$ \\
\hline Smart Grids & Energy & $\begin{array}{l}\text { Innovation science, science } \\
\text { and technology study, } \\
\text { humanity and social science }\end{array}$ & $\begin{array}{l}\text { Netherlands } \\
\text { (International) }\end{array}$ & $\begin{array}{l}\text { Private company and } \\
\text { citizens }\end{array}$ & $2016-2020$ \\
\hline $\begin{array}{l}\text { Strategic University } \\
\text { Network to Revolutionise } \\
\text { Indian Solar Energy } \\
\text { (SUNRISE) }\end{array}$ & Solar energy & Photo physics and chemistry & $\begin{array}{l}\text { UK } \\
\text { (International) }\end{array}$ & $\begin{array}{l}\text { Private foundation, Indian } \\
\text { government and citizens }\end{array}$ & $2017-2021$ \\
\hline $\begin{array}{l}\text { Transdisciplinary } \\
\text { Research Intervention } \\
\text { Anchored in Luxembourg } \\
\text { (TRIAL) }\end{array}$ & Environment & $\begin{array}{l}\text { Social Science, anthropology } \\
\text { and philosophy }\end{array}$ & $\begin{array}{l}\text { Belgium } \\
\text { (local) }\end{array}$ & $\begin{array}{l}\text { Politicians, economic } \\
\text { actors and citizens }\end{array}$ & $2017-2021$ \\
\hline $\begin{array}{l}\text { Urban ecology meets } \\
\text { architecture and urban } \\
\text { planning } \\
\text { (U-EM-A-UP) }\end{array}$ & Urban planning & $\begin{array}{l}\text { Ecology, urban planning, } \\
\text { landscape architecture, arts, } \\
\text { science communication, } \\
\text { environmental psychology, } \\
\text { cultural study and } \\
\text { environmental humanity }\end{array}$ & $\begin{array}{l}\text { Switzerland } \\
\text { (Local) }\end{array}$ & $\begin{array}{l}\text { Local government and } \\
\text { citizens }\end{array}$ & $2016-2021$ \\
\hline
\end{tabular}

\section{Rationale for transdisciplinary research}

Mono-disciplinary research has successfully addressed many scientific and societal issues, yet often fails in contexts with high complexity and uncertainty, where causal pathways transcend disciplinary boundaries. Multi- and interdisciplinary approaches can be helpful in such contexts but face analogous limitations when and where non-academic stakeholders hold knowledge uniquely critical to resolving the issue in question. In brief, TDR is required when other approaches are intrinsically unable to generate the needed insights and/or when the involvement of non-academic stakeholders is essential to successful implementation.

All TDR is solution-oriented, yet specific aims cover a range of goals and situations, e.g., some projects focus on local solutions and sets of actors within relatively prescribed themes, whereas others describe whole-of-society solutions for complex global problems (see Table 1 and the case vignettes in section 11). In general, TDR is valuable in several contexts:

- Where understanding and management of integrated systems requires cooperation among a range of disparate stakeholders.

- In situations involving systemic and rapid technological, environmental and/or social change, i.e. societal transitions. 
- In evaluating the societal impacts and/or best implementation strategy for a new technology or policy intervention or a suite of such interventions, particularly as they relate to a specific place or region.

- Where problems fundamentally involve the intersection of academic/technological and non-academic/societal domains.

- For scientific/technological issues in which ethical norms or value judgements have to be included in the problem solving and/or where solutions have real or perceived impacts on some stakeholders.

TDR can add significant value over mono-disciplinary or multi-disciplinary research in such situations, allowing for consideration of issues that the latter approaches would simply be unable to address. Yet, TDR is also applied to issues that are subject to more traditional research approaches. Given the generally greater complexity and resource requirements of TDR compared with traditional approaches, clarifying its added value is important. The case studies that were undertaken for this report, offer insights into why researchers adopt TDR approaches and their perceptions of added value at the practitioner level (see Box 1).

TDR is a mode of research and, as such, it aims to generate new scientific knowledge that is applicable to addressing societal challenges. It can have diverse social impacts, both during and beyond the lifetime of a project. Key examples, beyond the direct effects of interventions, include new relationships among citizens, stakeholders and academics; new capacities among partners and end-users; a space for societal dialogue wherein potentially hidden values and opinions are made visible; the empowerment and inspiration of stakeholders through their involvement in tackling societal problems; and the illumination of issues related to equity. By their nature, some societal impacts attributable to TDR are difficult to measure- because they speak to intangible changes in underlying attitudes or capacities, involve cascading impacts beyond the remit of a project, or encompass longerterm processes that exceed its timeframe. 


\section{Box 1. Messages from case studies: added value of transdisciplinary research}

Case studies highlighted a range of ways in which TDR can provide added value, from the perspective of a (scientific) principle investigator. In general, these fell into five categories.

I. TDR can address complex problems beyond the reach of traditional science, particularly those that require the application of contextual knowledge unavailable to researchers. Such is often the case in human-environmental systems, where the actions and incentives of practitioners and end-users can produce unexpected or unpredictable behaviour.

II. TDR can offer a practical way to address contested, high-stakes societal problems where knowledge is uncertain, the concrete nature of the problem itself may be disputed, and the potential impacts on stakeholders are significant.

III. TDR can add new dimensions and perspectives to traditional research approaches, and give rise to more innovative, holistic solutions. TDR approaches allow for the integration of practical/experiential knowledge, norms and ethical precepts in academic research and of abstract ideas with casespecific knowledge. In staging and resolving conflicts between different priorities and ways of understanding, it can foster the emergence of new questions, and the resulting process of resolution through debate can result in the enrichment and evolution of ideas.

IV. TDR can provide social benefits beyond pure scientific insights. It can provide venues for dialogue and conflict resolution around contested issues, address the expectations and fears of stakeholder groups or society at large. In providing a scientific perspective on ongoing social processes, it can act as a barometer for change, measuring progress or lack thereof and packaging information in ways that are meaningful for society.

V. TDR often generates significant lasting benefits. It can clarify in what circumstances or via what processes an intervention is likely to be accepted or taken up. It can foster societal acceptability and uptake by making an intervention familiar and developing the societal knowledge needed to make the most of it. Through TDR, society can develop relationships, tools, administrative structures and mechanisms that outlast individual projects and generate continuing benefits. TDR can be a powerful tool for capacity-building among individuals and institutions.

In many cases, longer-term societal impacts depend on networks and structures that are difficult to maintain beyond the end of a project, when funding and institutional support are no longer available. In such situations, social benefits may evaporate rapidly. Those involved in supporting and implementing TDR projects need to consider how beneficial structures and mechanisms that arise from these projects can be made sustainable.

\section{Key parameters of transdisciplinary research projects}

The definition and theoretical basis for TD remains contested, with different knowledge communities adopting different principles. Whilst this might be considered a purely academic consideration with limited practical relevance, it is problematic in that it divides the research and policy communities and is consequently a barrier to communication, mutual learning, and the consolidation of guidelines and best practices. As such, it also helps to explain why, even in projects that clearly recognise the need for transdisciplinary 
approaches, methods for participatory engagement, co-design and co-production are often ad hoc and sub-optimal.

For this report, TD is defined by the integration of academic researchers from unrelated disciplines and non-academic participants in creating new knowledge and theory to achieve a common goal. However, even under this definition, transdisciplinary efforts can vary widely. This variation can largely be characterised along 6 key dimensions that are introduced below.

\subsection{Breadth/diversity of interdisciplinarity}

All transdisciplinary efforts involve interdisciplinarity, but the number of disciplines involved and the epistemic distance among them will vary with the problem being addressed. In general - though not universally - the more separated the disciplines, the more difficult it will be to effectively integrate them. Differences among the institutional/professional frameworks and working modalities of the specific actors involved may also contribute to the complexity, and therefore the challenge, of effective TD.

\subsection{Depth of disciplinary integration}

Interdisciplinarity, by definition, involves the creation of new knowledge and theory and the blending of working modalities and heuristics. However, the degree of integration can be relatively more superficial or profound and may vary with the epistemic distance between the disciplines involved, the timeframe of investigation, and/or the complexity of the problem to be solved. In general, greater complexity demands deeper integration, given the likelihood of cross-disciplinary interactions, feedbacks and impacts.

\subsection{Degree/quality of interaction with non-academic participants}

TDR requires meaningful participation beyond the academy, yet the extent of interaction and the degree to which outside stakeholders influence the research process will differ from project to project. Among determining factors are the technical complexity involved, the resources available, and the timeframe. The capacity of relevant local non-academic stakeholders can also dictate the form of participatory engagement. True TD requires that participation by non-academics is more than mere tokenism-thus, stakeholder consultation without a mechanism for incorporating suggestions fails to be truly TD. Yet, when non-academics make all decisions and hold all power, research becomes mere consultancy (Arnstein, 1969 ${ }_{[13]}$ ). TD should operate at the level of partnership, wherein planning and decision-making responsibilities are shared and not subject to unilateral change.

\subsection{Composition of non-academic partnerships}

The nature of TDR projects depends strongly on which non-academic partners are included. For example, projects carried out in partnership with private sector actors are likely to have a different flavour and orientation than those that involve community-based or civil society organizations. In general, external stakeholders fall into one of four categories: private sector (i.e., business and industry), public sector (i.e., government and civil service), civic sector (i.e., civil society and non-governmental organizations), and citizens/communities themselves. Traditional and modern media may also play an important role. Many non-academic stakeholders have no formal science education but they are experts in the respective fields and can provide insights that go beyond academic knowledge. 


\subsection{Timing of participatory engagement}

The degree of engagement of researchers with non-academic participants is rarely constant. Most TDR projects feature phases with active participation and others with greater focus on pure research, in some cases, alternating periodically (see Figure 3) Timing must be considered not only in light of research phases and funding cycles, but of the cadences of non-academic life. For example, political, fiscal, or business cycles can greatly influence both the structure and the efficacy of transdisciplinary efforts, depending on which external stakeholders are involved.

Figure 4. TDR project lifecycle, illustrating phasing and depth of participatory engagement

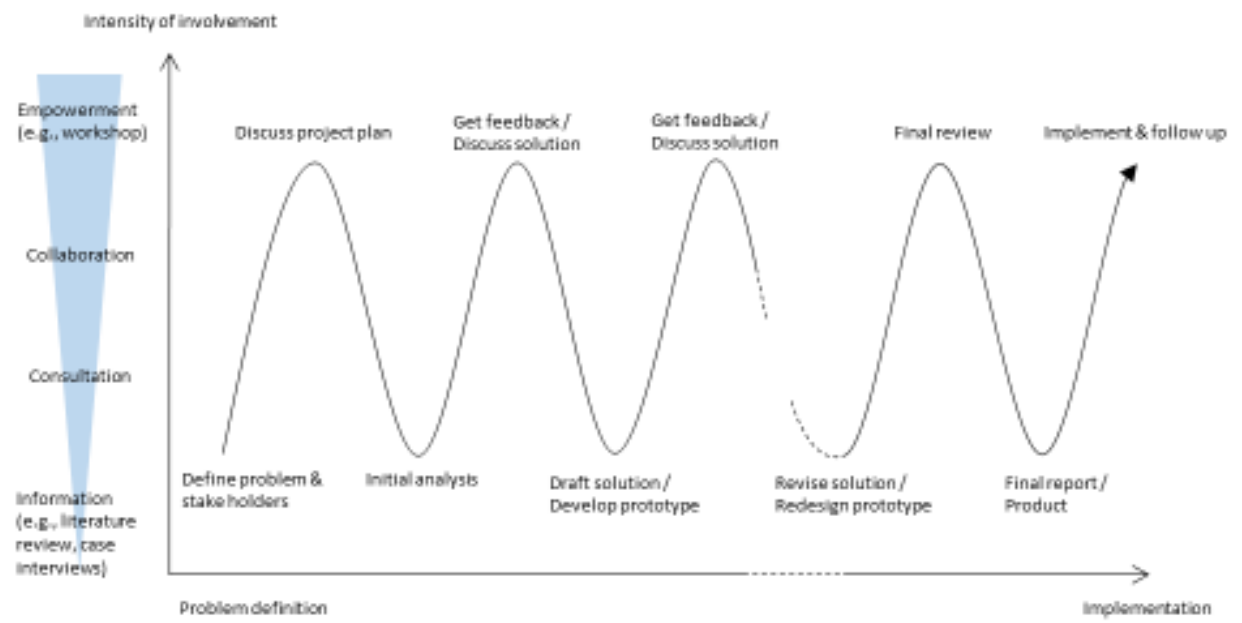

Note: The oscillating line shows the dynamic and iterative nature of the TDR process. Source: Adapted from Stauffacher $\left(2008_{[14]}\right)$.

\subsection{Types of knowledge}

TDR often blends knowledge at different scales (e.g. context-specific vs. generalised), with different functions (e.g., phenomenological vs. strategic), and from different sources (e.g. experiential vs. scientific/theoretical) (Enengel et al., 2012 $\left.{ }_{[15]}\right)$. The extent to which different types of knowledge are emphasised influences the character of TDR projects.

The case studies that were carried out for this work give relevant insights into how these 6 key parameters impact on the design and implementation of projects, with implications not only for individual project participants but also for institutions and sponsors. Some of the key messages from the case studies, in this regard, are summarised in Box 2. 


\section{Box 2. Messages from case studies: TDR project design and implementation}

Respondents to case interviews identified several fundamental characteristics of TDR that should inform problem framing and project design.

TDR generally takes longer and requires more resources than traditional research, both because a diversity of partners must become familiar with one another, but also given the need to develop ways of working, decision criteria and shared goals that draw on the norms, operating procedures and knowledge of all sets of stakeholders.

The planning and engagement phases are likely to pose the greatest difficulties in establishing mutual understanding and coordination. They are also the period when goals and expectations are most likely to evolve; projects should be aware of this and devote sufficient time to overcoming barriers and to exploration. TDR often requires significant elasticity-goals, processes, relationships and hierarchies can shift during project implementation, opportunistically or based on evolving insights. Such considerations need to be discussed and clarified with funders a priori.

In selecting project partners, consideration should be given not only to disciplinary or sectoral requirements, but to prior experience with TD and to empathy, openmindedness, sensitivity, and social skills. TDR generally requires a strong understanding of the nature of a given place (i.e., of culture, history, institutions, power and relationships in the geographic area of interest), and the research team-including non-academic partners-should be selected accordingly. As such, inclusion of experts or knowledge brokers with deep connections to local communities and actors, or who play a natural role in facilitating relationships among stakeholders, is important. In many projects, pre-existing relationships that have generated mutual trust and shared practical experience are beneficial. At the same time, it is clear that the selection of both academic partners and stakeholders must reflect the specific nature of the challenge to be addressed.

Effective TDR requires structural mechanisms to manage complexity. Project management requires significant, dedicated (i.e. rather than ad hoc) resources. It is often the case that some mix of nested, multi-level and cross-disciplinary governance structures must coexist with unifying thematic or locality-specific structures. Effective project management may need to be supported by formal agreements on issues such as dispute resolution, changes to project goals or advisory arrangements and budgetary management. There can be value in having external, independent, impartial advisory structures.

Effective communication within complex TDR projects serves various roles, including increasing efficiency, building trust among partners and ensuring the rigour of results. Different stakeholders can have different standards, expectations, and incentives for communication-for example, some stakeholders may be reluctant to report negative results. In all contexts, TDR requires regular and consistent communication across the research team and partners. Where possible, physical proximity (e.g., housing research partners under one roof) can be beneficial. In some cases, it has proven essential to have a designated and skilled facilitator to manage relationships and communication.

Leadership across academic disciplines and other stakeholders in the project team can be delicate, especially where mandates and/or lines of authority are unclear. Co-leadership, with academic and non-academic leaders, is often desirable. In any case, projects should explicitly establish equivalent standing (or justifiable hierarchies) among members of the project team and procedures to resolve conflicts. Indeed, TDR requires explicit and continual negotiation: about values, goals, ways of working, definitions, criteria for success, division of labour and other issues-this must be built into project processes. Competition among partners and between different types of 
partners with potentially conflicting incentives (e.g., civic and private sector) can impact progress and success needs to be carefully and proactively dealt with.

Managing expectations is another major challenge. The breadth of work involved in many projects can lead to loss of enthusiasm among partners who don't see particular elements as related to their personal or professional objectives. For researchers, expectations about publication of academic results can be particularly thorny, given differences among disciplines-indeed, this poses a major barrier to involvement of young scientists in TDR. Conversely, societal partners naturally have expectations around the communication of results - these can be particularly challenging when the local language differs from that in which academic results would normally be communicated. Private sector partners are likely to have expectations about ownership of intellectual property and profit-sharing. Because TDR generally involves pressing societal problems, expectations and pressures can be greater than in traditional research, with failures resulting in a loss of confidence on the part of project partners. In general, proactive, a priori negotiation and an equitable balancing of transdisciplinary elements with more focused research can help manage expectations across the wider set of project stakeholders.

Capacity development, both within and beyond the research team, is valuable for instilling a sense of ownership, as well as for sustaining project results. Within research teams, it is important to consider the career needs of young researchers; while TDR skills and competencies are marketable, early-stage researchers need both stability of employment and relevant academic outputs. Formal and informal training activities for non-academic partners are an integral part of many TDR projects.

\section{Research system challenges for the effective implementation of transdisciplinarity}

There is considerable experience in TDR across several research fields (see Figure 3 ) and a number of useful guidance documents and toolkits have been developed. ${ }^{5}$ Some institutions have specialised TDR support services (see Box 3) and sponsors are developing criteria and processes that account for the specific requirements of TDR (see Box 4). Nevertheless, even with optimum project design, conducting TDR means overcoming numerous barriers embedded in most research systems. These are discussed in more detail below.

\subsection{Scientific disciplines and institutions)}

"terminology differences between sectors/fields are a barrier" 6

"there are often tensions between disciplines"

"Integration between more related disciplines can be more difficult than between more widely separated disciplines, both because of approaches and expectations and because of institutional barriers"

Scientific disciplines support the creation and consolidation of information within relatively well-defined branches of knowledge. They share the common framework of the scientific method, but develop characteristic tools, language, ways of working, and criteria for evaluation. These disciplinary heuristics serve to facilitate communication, standardise the presentation of information, and establish a shared basis for valuing research and rewarding success. In parallel, disciplines create organisational and professional structures to support training, career advancement, research implementation, collaboration, and 
knowledge dissemination, exchange and synthesis. New disciplines or disciplinary subspecialties may emerge in response to paradigmatic shifts, scientific spill-overs, increases in available data or the development of new types of data.

While disciplinary structures and heuristics are of considerable value, they can be a formidable barrier to effective TDR. In general, disciplines that are more distant in terms of their focus (e.g., natural sciences versus humanities) will face greater challenges working together-although this is not universally true and depends on the specific heuristics and structures of the disciplines involved. In some cases, disciplines may actively discourage cross-disciplinary work to maintain disciplinary integrity, or due to a perception that other disciplines produce invalid or less valid information. Conversely, interdisciplinary research (and to an even greater degree TDR) relies on an acceptance by all parties that different perspectives each yield valuable knowledge and that their combination is likely to provide improved utility.

The traditional organisation of academia and associated structures in universities and research institutions tends to constrain work that crosses disciplinary boundaries. While individual researchers may straddle or connect disciplinary 'silos' to initiate and implement multi- or interdisciplinary research within existing systems, substantive transdisciplinary initiatives can be difficult to establish for structural reasons. Differences in expectations, capacities or rules across institutions can complicate management and inter-institutional collaboration, especially where individual institutions impose barriers that constitute bottlenecks for entire projects.

There is considerable potential for different types of institutions, e.g. research universities, technical universities and public research institutes to combine expertise in TDR projects. Notably, academic institutions focusing on applied sciences or research are more readily able to take on and effectively manage TDR, yet these rarely operate on an equal footing with traditional research institutions in terms of finances. Moreover, they maybe viewed as less academically reputable, which tends to constrain the sharing of complementary expertise and networks.

\title{
6.2. Data management
}

\author{
"A major issue is integration of data of many types from many different sources." \\ “....significant differences in spatial and temporal resolution, timing of acquisition, level \\ of analysis (individual/group/institution) and type (quantitative/qualitative) of data"
}

"Protecting data effectively requires close communication, especially when it originates from different stakeholder domains"

The organisation of scientific information generally reflects the disciplines or domains from which it derives, with research communities managing the information generated and used in their own fields. Infrastructures, standards and processes are thus optimised for internal use, posing challenges when new research communities attempt to access and use data from other fields. There are significant technical and cultural obstacles to the practical realisation of data integration, which is a prerequisite for TDR. Moreover, as TDR often addresses issues that have a significant social or health component, some of the necessary data may be subject to personal privacy or security regulations and ethical considerations. Where the private sector is involved, commercial interests and intellectual property rights (IPR) may also have to be considered. Whilst different communities are used to dealing with these issues in their own domains, TDR, by definition, brings together multiple research and stakeholder communities, who are most often not familiar with the data handling conventions of their counterparts. In addition, the integration of data from diverse 
sources can give rise to new regulatory or ethical issues, e.g., de-anonymisation of personal data.

\subsection{Academic and professional training}

"Universities and research institutions can take a lead in developing and requiring TDR training."

"Need a positive learning environment allowing exchange between researchers at different levels."

"Process of TDR is too long and complex to meaningfully include students."

Higher educational systems prepare students to deliver contributions in prescribed disciplinary fields, building expertise and acquainting them with the terminology, methodologies, and modes of professional interaction and knowledge transmission characteristic to those fields. These systems may, by their nature, be a barrier to TD - for example, doctoral theses may be restricted to within disciplinary boundaries.

Universities and other academic institutions can play important roles with respect to TDR, training young researchers to meet the specific challenges of transdisciplinary projects, including effective communication across disciplines, engagement with non-academic stakeholders, and complex project management ${ }^{7}$. Similarly, they can familiarise researchers with the tools, terminology and methods of TDR. At the same time, training for TDR must be balanced with the ongoing need for substantive disciplinary knowledge.

Beyond providing stable platforms for the development of TDR skills and professionalism, educational systems have a major role to play in elevating the perceived value of TDR among students, established researchers, research funders, and non-academic actors. This role is contested; indeed, some academic advisors may discourage students from pursuing TDR where it is viewed as of questionable value or as career-limiting.

\subsection{Career advancement for researchers}

"Limited number of positions for interdisciplinary researchers (e.g., in disaster prevention) leads managers/advisors to push young researchers toward conventional fields, which universities prioritize to demonstrate results."

"..strong dissonance between desire of researchers to carry out interdisciplinary research and reality of research sector requirements; e.g., can't register an interdisciplinary thesis in two schools."

"TDR competencies are in high demand, but no corresponding mechanisms to provide career value for those who possess them."

As with funding, the career advancement system for scientists is closely tied to disciplinary priorities and publication. Because TDR takes longer than traditional research and often leads to fewer publications - or to publication outside traditionally esteemed disciplinary journals - it can be career-limiting. Moreover, while TDR experience and competencies are highly valued within individual projects, they are not highly rewarded within academic systems of career advancement. Thus, despite high interest, it is difficult for young researchers to pursue TDR. It may be easier for more established researchers with robust publication records, extensive collaboration networks, and secure careers. New mechanisms to recognise and credit high-quality TDR outputs, including non-academic outputs, and to value transdisciplinary competencies need to be built into existing systems for hiring, promotion, and tenure. This may require new metrics for measuring impact across science and society (see ahead, 7.5). 


\subsection{Jurisdictional boundaries and international cooperation}

"Regulation for water issues would require an interplay of national and international legislation."

"Language and cultural barriers can be major obstacles in multi-country collaborations."

"Need an international liaison office to assist international collaboration, including legal frameworks, contracts, language."

The types of pressing societal issues that demand transdisciplinary solutions are often international or global in nature, and likely to cross-geographic and jurisdictional boundaries, just as they cross-disciplinary and organisational boundaries. In these contexts, TDR may have to accommodate different legal and regulatory regimes - for example, around appropriate use of data, ethical research, or material transfers - and differences in language, culture, norms and ownership. Each of these poses significant, yet different, challenges for communication, harmonisation of the research effort, organisation and dissemination of results, and coordinated action, while also introducing significant complexity, time and costs. Transboundary challenges can arise at the project or the funding programme level and require dedicated management.

\section{Box 3. What are Universities and public research institutions doing to promote TDR?}

Universities and research institutes have taken various approaches to promote TDR. These range from the physical co-location of researchers from different disciplines to encourage exchange and collaboration and the co-teaching of relevant courses, to the development of standard practices and policies for transdisciplinary projects and the establishment of dedicated inter- and TDR centres or networks. The following examples illustrate some of these innovative efforts:

The Université catholique de Louvain (Belgium) hosts LPTransition, a cross-disciplinary, cross-sectoral scientific research platform which aims to explore pathways for ecological and societal transitions from a transdisciplinary perspective. LPTransition aims to collectively support the development of TDR trajectories in research teams at UCLouvain

The Institute for the Future at the University of Leuven (Belgium) is a research incubator that supports, catalyzes and accelerates TDR at KU Leuven. It supports transdisciplinary education and capacity building, bringing students representing different disciplines together with experts and societal stakeholders around problems that require TDR approaches. Interesting ideas emerging from these teams are incubated to assess their feasibility and sustainability.

The Leuphana University of Luneburg (Germany) has created an interfaculty Methodology Centre as a focus for TDR development and support, while at the same time appointing new transdisciplinary professors in different departments in order to institutionalise TDR approaches.

The Technical University of Berlin has developed a transdisciplinary strategy that is championed at the highest leadership level and promoted by the University's Executive Board, with a major emphasis on cooperation with the citizens of Berlin. A dedicated team at the University organises consultation workshops and trialogues to identify topics and project ideas and coordinate funding applications.

The University of Tokyo's Institute of Gerontology (IOG) is a cross-sectoral structures that brings together researchers and students from different faculties and 
graduate schools with employees seconded from private companies and local government. In order to promote research on the problems of an aging society, IOG has concluded agreements with local governments and formed an academia-industrial network - "Gerontology" - that conducts research to support individual autonomy.

The Université-Grenoble-Alpes has been created by a merger of different preexisting universities in the region and it has based its development project on promoting a number of major cross-disciplinary projects, in order to connect the different research communities. Most of these projects address complex societal challenges and several integrate stakeholders from outside the academy (e.g. Mobilair case).

The CRI-Centre de Recherche Interdisciplinaire at the University of Paris Descartes (with participation of Grenoble Alpes Université and INSERM-National health institute) has been created to promote education and learning for the implementation of the UN Sustainable Development Goals. The aim of the Centre is to create and develop at scale the capabilities to articulate individual and collective action for the planet by using a "learning by doing" approach. It organises inter-and trans-disciplinary workshops and living lab activities and sponsors projects.

The University of Technology in Sydney has a mission to integrate fundamental research with leadership in implementing sustainable solutions at the local and regional scale. The achieve this, it has established a number of sustainability research centres in areas such as climate change, energy technology conservation, water management and sustainable futures. These bring together different disciplines and work with government, industry and community partners to identify solutions and implement change.

Arizona State University, which is ranked as one of the top universities for research and innovation in the USA has an overall mission "....to advance research and discovery of public value; and assuming fundamental responsibility for the economic, social, cultural and overall health of the communities it serves". It is organized into 17 colleges, with more than 170 cross-disciplinary centres and institutes, many of which active engage with non-academic stakeholders to develop implementable solutions to complex real-life problems (see for example, the ASU-DCDC case).

The Swiss Federal Institute of Technology for Environment and Sustainability under the aegis of ETH, is being created out of the merger of two previously independent environmental research institutes. This major restructuring is linked with the strategic goal of ETH to strengthen inter- and trans-disciplinary research that will generate innovative solutions for a sustainable society.

Delft University of Technology educates its students to contribute to solving societal challenges by providing them "with a solid grounding in interdisciplinary skills, sustainability and entrepreneurial thinking". It incentivizes TDR, among other things, by connecting its disciplinary faculties through cross-cutting institutes that facilitate interdisciplinary research around societal challenges and collaborate with nonacademic stakeholders, including the industry and policy-makers.

In addition to these examples, several of the project case studies for this report highlighted the critical importance of investment, management or structural developments at their host Universities in enabling TDR. These examples include structural investment at the University of Leeds, UK (Pig Sustain) and the establishment of a cross-disciplinary structure at Tohoku University in Japan (see IRIDeS). The JapanASEAN STI Platform (JASTIP) is an interesting example of a distributed international TDR centre.

Some of the project cases demonstrated the importance of Public Research Institutions as a focus for TDR. Hence in Germany, the Institute for Technology and Systems Analysis has a focus on transitions to sustainability (CuveWaters) and in Norway the 
Institute of Marine research is an interdisciplinary institute, whose mission includes supporting innovation and sustainability (see CRISP).

\subsection{Funding and evaluation of research proposals}

"TDR applications often fail due to not fitting traditional field descriptions."

"Funding is available for research component, but insufficient for real involvement of non-academic stakeholders. At least 50\% extra time and funding needed."

\section{"Lack of funding in framing phase was difficult."}

In most contexts, science funding mechanisms are aligned with disciplinary structures, and thus dedicated funding is relatively scarce for TDR. Research assessment and competitive grant awarding processes invariably depend on peer review that focuses on scientific excellence, organized along disciplinary lines. The diversity of disciplines within individual transdisciplinary projects might seem an advantage in terms of accessing distinct funding opportunities, yet few of these countenance transdisciplinary approaches. Even where research funding agencies or national strategic funding priorities recognise the need for inter- and transdisciplinary research, this can be difficult to map onto existing operational mechanisms and review criteria (Pohl et al., 2011 $1_{[16]}$ ). For example, assessing the merits of TDR proposals may fall to mono-disciplinary panels that lack experience in TDR and do not understand its requirements. Efforts to mobilise TDR through traditional review routes may lead to disparities in funding for different project componentsincluding where funding is earmarked for disciplinary research activities, thus neglecting the broad engagement which is essential to TD.

The diversity of actors involved in TDR opens some new avenues for funding beyond traditional academic or state science funding mechanisms. For example, TDR can draw on corporate sources or on funding allocated for social or economic development in a variety of sectors. Innovative funding structures can promote the involvement of relevant stakeholders, including businesses and local communities. Yet the existence of new and multiple funding sources with different rules and processes can also complicate management of TDR.

Funding tends to reflect societal and scientific norms and established power relations. TDR often challenges such norms, fundamentally requiring power to be shared among nontraditional stakeholders. Moreover, it tends to focus on controversial societal issues involving conflict among a variety of actors, and therefore entails greater risks than traditional research. These factors may decrease the incentive for relatively conservative funding systems to foster TDR.

The emergence of TDR projects requires competitive funding geared to its needs and realities. In addition to dedicated peer review and active programme management significant time and resources are necessary for the initial co-design phase of project (see Figure 4). Funding for this is rarely available under traditional research funding schemes. In general, TDR is more resource-intensive, time-consuming, risky and prone to shifting goals than traditional research. While it can yield proportionally greater benefits, it requires more stable, reliable funding sources and a priori recognition of these challenges. 
Figure 5. Conceptual model of a TDR funding programme

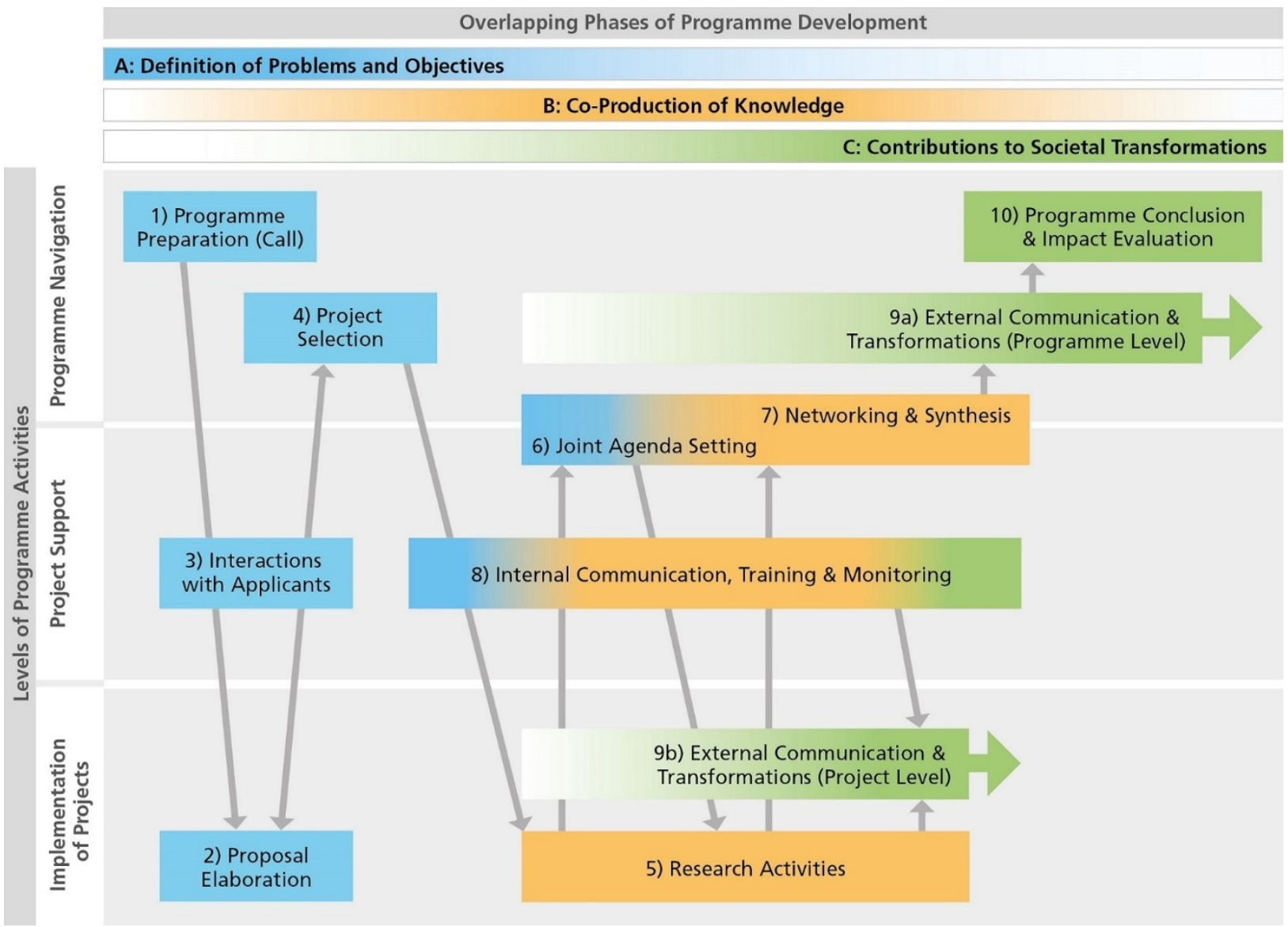

Note: A conceptualised programme design and management model for TDR involves 10 key stages (the width of the symbols represents the relative importance of the stages over time

Source: Research funding programmes aiming for societal transformations: Ten key stages. Science and Public Policy (Schneider et al., 2019[17]).

Research funders are in many cases responding to these needs by building dedicated programmes around TDR. Typically, such programmes require transdisciplinary approaches and ensure transdisciplinary competence in assessment panels. In the best cases, they also have long-term time horizons, enabling research communities to plan future activities. In some cases, they are challenge-driven, dedicated to a particular policy priority, and they may cover activities from research to market, including innovation-related action (see box 4).

\subsection{Research publications, incentives and rewards}

"In most contexts, TDR publication is more difficult than traditional publication and traditional journals are rarely interested in TDR publications."

"Publication of TDR can be fostered by creation of TDR-specific journals or by influencing top journals to value TDR. Both pathways have value, but new journals are generally less influential and less likely to be positively evaluated by disciplinary bodies."

"Current standards for success in science offer no incentive for TDR."

The traditional system for scientific publication is founded on academic peer-review processes rooted in disciplinary structures. Whilst citation patterns of transdisciplinary 
research papers have not been systematically studied, there is some evidence that interdisciplinary work receives less attention on average than traditional research at the level of both journals and individual articles (Barthel and Seidl, 2017 ${ }_{[18]}$ ). This may reflect the challenges of producing interdisciplinary research that meets traditional standards of excellence or the structural incentives that encourage scientists to pursue and cite mono-disciplinary work in their own fields. It is clear also that some transdisciplinary papers, in areas such as public health or ecosystem services, do manage to transcend these challenges and are highly valued and acknowledged by scientific peers.

As publications are generally considered to be the most valuable output of scientific research - and by extrapolation the primary measure of both individual and institutional performance - they play a critical role in determining career paths (see earlier discussion) and allocation of research funding. Hence, barriers to publishing TDR research are a strong disincentive to the very conduct of such research. Whilst disciplinary advances can be made (and published) in the context of TDR projects, the publication system will need to evolve to provide fair and rigorous review for integrated TDR outputs in many different fields.

\section{Box 4. What are Research Funders doing to support TDR?}

Research funders in many countries are striving to promote TDR through the development of dedicated grant programmes. These programmes tend to differ in a number of ways from regular competitive research funding programmes. Hence, they may have different criteria, proposal definition, preparation and review processes and award management and monitoring procedures. Some illustrative examples are given below.

The NSF Convergence Research Programme focuses on novel research at the interface between different disciplines (and other stakeholders). It has established a reviewers' college of leading scientists who are given special training to help ensure that they can fairly assess inter- and trans-disciplinary proposals. Projects are actively managed and reviewed after two years at which point they may be discontinued.

The Brussels Institute for Research and Innovation (Innoviris) has launched a research program called "Co-Create" that funds research and innovation projects based on Participatory Action Research Principles (PAR) in the fields of Urban Sustainable Food Systems and Urban Resilience. The projects are carried out in experimental spaces directly in the users' living environment, where usage is the main driver of innovation. The Co-Create action aims at reinforcing the relevance of the innovations for urban resilience within the Brussels-Capital Region (Hulhoven, n.d.[19]). This research program is the first of its kind in Belgium which makes it very innovative and experimental both in terms of the type of projects funded and the funding allocation process. For instance, the selection and evaluation of the projects is done by a mixed panel of experts (researchers, social workers or other field workers) in the relevant domain, and also by a jury composed of citizens.

Germany's Research for Sustainable Development (Forschung für Nachhaltige Entwicklung FONA) initiative aims to develop decision-making tools for future-oriented action and deliver innovative solutions for a sustainable society. Under its third framework programme (FONA3), the Federal Ministry of Education and Research (BMBF) supports sustainability research in Germany. A multi-stakeholder agendasetting was carried out to define research priorities. There are three flagship initiatives: Green Economy; the City of the Future; and the Energy Transition in Germany. These are designed to be application-oriented, and include stakeholders, such as businesses and local communities. (see also the APV-RESOLA case vignette). 
Japan has a number of programmes that support TDR. The Japan Science and Technology Agency (JST) manages the Centre of Innovation (COI) programme to promote collaboration between the private sector and academia and projects must have co-leaders from each sector. COI projects use a back-casting co-design approach focussed on societal problems. They receive funding not only from JST but also from private companies and many involve multiple stakeholders (see Mobility case study). The RISTEX programme (see the report on open research agenda setting (OECD, $\left.2017_{[20]}\right)$ ) uses a proactive and iterative management process to develop and support trans-disciplinary research projects to address complex problems at the local community scale. The Government of Japan's Cross-ministerial Strategic Innovation Promotion Program (SIP) aims to realize innovation beyond the framework of government ministries and traditional disciplines and again includes support for TDR as well as broader innovation actions.

The UK Global Challenges Research Fund (GCRF) is a GBP 1.5 billion fund announced by the UK Government in late 2015 to promote challenge-led research with a focus on developing countries. The initial funding was for 5 years, during which time a number of interdisciplinary research nodes have been established in UK Universities. This required a considerable amount of negotiation between the funders and Universities but is driving systemic change.

France have reorganized its National Research Strategy for 2014-2020 along a set of societal challenges. This implies breaking the walls between fundamental and applied research, researchers and stakeholders, which requires interdisciplinary and transdisciplinary approaches. This strategy, led by the Ministry of Higher Education, Research and Innovation (MESRI), is being implemented by a series of programs at national, European or international level. Each involves ad-hoc committees, with appropriate expertise and experience, to select project that are funded by the National Research Agency (ANR).

Following the engagement of citizens in developing a national research agenda, NWO in the Netherlands has implemented a dedicated funding programme for collaboration between knowledge institutes and social partners to study urgent issues, including those identified the national agenda. The Research Along Routes by Consortia (NWA-ORC) programme has a three phase submission process: initiatives, pre-proposals and full proposals.

Norway's Collaborative and Knowledge-building Project provides support to national research organisations that apply in cooperation with relevant actors from the private and/or public sector. The objective is to promote cooperation and develop R\&D expertise and capacity in areas of importance to society and business and industry.

The European Commission's 'Science with and for Society' SWAFS programme is targeted at European societal challenges and aims to build capacity and develop innovative ways of connecting science to society. It supports all societal actors (researchers, citizens, policymakers, business, non-governmental organisations etc.) to work together during the entire research and innovation cycle. Many of the projects within this Responsible Research and Innovation (RRI) programme are transdisciplinary and the programme design includes an open on-line consultation process.

The Belmont Forum, brings together national funding agencies and organises codesign workshops to develop its collaborative research actions, which are all interdisciplinary and many of which are transdisciplinary. This forum has close links with the Future Earth initiative, which provides a global framework for sustainability research under the aegis of the International Science Council.

The Leading Integrated Research for Agenda 2030 in Africa (LIRA) programme is managed by the International Science Council with funding from the Swedish Development Agency. This programme supports TDR projects in African countries. It 
has implemented a multi-step proposal development and review process, including training workshops for applicants who pass the $1^{\text {st }}$ stage of review.

\section{Challenges for transdisciplinary research extending beyond research systems}

"TDR can foster ground-breaking cooperation between historically antagonistic groups, with science functioning as a neutral interface."

"Scientists must display high professional competence to be taken seriously in tackling societal issues."

Beyond securing insights and information essential to addressing complex societal challenges, the inclusion of stakeholders from outside of academia in research processes has other important potential benefits. These include promoting ownership and uptake of research results and solutions; nurturing understanding of science and its processes and growing trust in science. Yet, the inclusion of non-academic stakeholders also raises a number of issues relating to research integrity, credit and acknowledgement, equity and ethics - in the first instance at the level of individual projects, but also with broader implications for science policy.

\subsection{Engaging non-academic stakeholders in transdisciplinary research}

Effective inclusion of non-academic stakeholders in TDR requires an understanding of their potential contribution and expectations and the processes needed to sustain and derive greatest value from their participation.

Non-academic stakeholders vary widely in their incentives, ways of working, language and capabilities - both within and across sectors. They tend to act, react and evaluate knowledge in different ways to academics, and they often have access to information unavailable to researchers. Indeed, non-academic stakeholders can provide critical insights and challenge the assumptions of academics - in some cases, such insights lead to reevaluation of goals or changing of project activities. Often, non-academic stakeholders have more power to act, and are better positioned to overcome barriers (e.g., language, institutional, bureaucratic, legal) than researchers. As such, securing their 'buy-in' is critical to implementing interventions. Non-academic stakeholders are often also in a better position to evaluate societal impacts and feasibility of interventions than researchers.

Non-academic stakeholders play various roles in TDR projects. In some cases, they are the primary drivers of demand for the research. While engagement in TDR projects is usually iterative, non-academic stakeholders often play significant roles both at the beginning of the process, where broad preliminary consultation is undertaken to establish goals and clarify relationships, and toward the end, when projects tend to shift from fundamental research or technology development to implementation and diffusion. In some cases, nonacademic partners have significant capacity for scientific research, and may thus be involved on a more continuous basis. Elsewhere, technology transfer and training for societal partners may be explicit goals. Engagement is typically multifaceted, and the timing is often driven by non-science factors. While co-leadership is the ideal, in practice TDR projects are often led by academic researchers and relationships vary widely.

Various processes are critical to establishing and maintaining effective participation of nonacademic stakeholders. Understanding the incentives of the specific groups involved is critical; for instance, whereas businesses may react negatively to perceived threats to their activities or profit, scientists may have concerns about the publishability of results. 
Moreover, neither all scientists nor all businesses (nor other stakeholder groups) are alikefor example, small businesses may be more dynamic and innovative, but are also much more vulnerable, than large businesses. It should not be assumed that understanding across stakeholder domains will emerge spontaneously - in fact, elucidating potential conflicts can require significant, dedicated effort. Engagement often involves explicit negotiation, for example of the allocation of funding among partners, the distribution of benefits arising from research, the nature of quid pro quo relationships, or even of direct payment of non-academic stakeholders for their participation. The natural complexity of TDR may discourage participation, but candid negotiation, along with standardization of protocols and agreements, can help.

Where there are significant differences in perceived power or authority among different stakeholders, specific processes may be required to allow for more open, equal exchange; for example, at Nagoya University COI certain individuals from business and local government are designated "social implementation leaders", a designation which empowers them to offer opinions to academics in positions of high authority (see Mobility case vignette).

\subsection{Ethical considerations}

Most TDR incorporates a strong equity dimension by virtue of its orientation towards societal problem-solving and its incorporation of non-academic stakeholders. Similarly, while TDR is bound by the same ethical considerations as traditional research, it will often require greater attention to these issues as a consequence of its societal framing and direct impacts. Ethical issues can arise both in the design and management of TDR projects and in the practice of TDR. Some of the issues that require careful attention in TDR are described below.

Diversity and inclusivity of partners are important ethical considerations: project stakeholders should be chosen not only based on technical, disciplinary or sectoral proficiency, but to represent those groups who will be impacted by the research and any implemented solutions. This often implies a high diversity of backgrounds and worldviews in project teams; as such, it is important that TDR projects incorporate the expertise needed to understand all stakeholders' needs and positions, and to resolve conflicts; this may include, for example, expertise in psychology, law, culture, policy or specific languages.

Gender balance and diversity of individuals across different project partners are normally important considerations. Complex societal issues invariably concern both men and women and normally cut across different societal groupings. Hence, it is important that these different perspectives are included in TDR that attempts to address these issues.

Asymmetries of power can exist between different academic and non-academic partners and knowledge production itself can accentuate these asymmetries. Over the life of a project, there is a need to continually identify and mitigate power differentials. Ethical conduct demands honesty and transparency in dealings with end users, as well as meaningful engagement of all stakeholders, i.e. engagement should carry with it a reasonable expectation of affecting project goals, processes and actions

Cultural equity and/or language issues can be important considerations. This is frequently the case in international projects but these issues can also be important in local scale projects. Because effective communication is critical in TDR, ensuring sufficient language proficiency on the project team is often important

Data access and who controls access can be a particularly sensitive issue. This relates not only to personal data and other forms of sensitive data, which cannot be made openly 
available, but it also relates to the broader issues of responsibilities and rights to access and use data, both during the course of a project and after it completion .

Equitable distribution of risks and benefits: Well-designed TDR projects proactively identify potential winners and losers, especially with respect to vulnerable groups and take measures to balance risks and benefits. Stakeholders have different incentives, some of which may conflict with each other and these need to be recognised and addressed in an equitable manner.

The potential for unintended consequences of the implementation of an intervention. These consequences can extend to groups that are not directly involved in a project and hence have 'no voice'. Outreach and consultation activities that extend beyond project partners are one way to explore unintended consequences

Not every ethical concern is relevant to every TDR project, and some issues only arise or become apparent during the course of project activities. Accordingly, while a priori ethical approval should be an integral part of TDR, ethical review is an ongoing process, salient over the life of a project.

\section{Monitoring and impact assessment of transdisciplinary projects}

Inter- and transdisciplinary research projects are highly heterogeneous, challenging the development of generalised frameworks for monitoring and assessment of both project functioning and project impacts (Klein, 2008 ${ }_{[21]}$ ). Moreover, the measurement and evaluation of the societal impacts of TDR are challenging because of non-linear dependencies, multiple interacting drivers, and relatively long, uncertain time scales for realising "impact" (Roux et al., 2010 [22] $)$. New frameworks are needed to assess a priori the likelihood that projects will be successful, to ensure their continued effectiveness once initiated, and to measure their impact upon completion.

Complex TDR projects (and programmes) require dedicated management tools and processes, which can aid in effective monitoring. For certain projects, depending on their scale, policy-cycle management methodologies (e.g., log frames) derived from development or business may be useful. Likewise, regular contact with sponsoring agencies and or external advisory or steering committees can be useful.

Monitoring and assessment should be distributed, with different criteria assessed at timescales appropriate to the various components and aims of TDR (e.g., scientific rigour, citizen feedback, logistical efficiency). Given the experimental nature of TDR, monitoring must often be more flexible than for traditional research, recognising shifting goals and priorities. TDR can also be more risky, i.e. the outputs are less predictable than more traditional research approaches, and it can be expensive. The costs and potential benefits need to be evaluated not only at the outset of a project but at regular intervals during its implementation. This can require active project management from the project sponsor(s).

In general, ex post evaluation processes should consider the extent to which TDR projects benefit all stakeholders. In contrast to typical academic projects, valid deliverables from TDR projects will include both qualitative and quantitative outcomes and both academic and non-academic outputs. To properly assess the latter, assessments can be solicited from non-academic actors and beneficiaries of the research, with due attention to potential conflicts of interest. Depth and quality of participation and visibility (e.g., in media or political statements) may themselves be valid assessment variables for TDR, as may the extent of new investment or funding for a societal issue.

Assessment processes for TDR need to take into account the reality that impacts on both science and policy may not be realised immediately and can be difficult to estimate. For 
example, the emergence of new frameworks for thinking or new ways of working can be intermediate outcomes of significant value that are not always acknowledged in evaluations.

Pathways-to-impact and theory-of-change approaches can be useful in visualising impacts and articulating goals. As discussed earlier in section 3, there are a number of overlapping concepts and different communities that have been using TDR-related approaches in different contexts. The development research community and clinical research community have developed their own impact assessment approaches and there are considerable opportunities for mutual learning across different sectors.

\section{Case study vignettes}

This section includes short summaries of each of the case studies that were interviewed for this report (tables 1a and $1 \mathrm{~b}$ ). Whilst previous sections have drawn heavily on this case work and have included selected extracts from the interviews to illustrate specific issues, the individual case reports can help the reader understand how these issues manifest at the operational project level. Each case vignette includes a small number of lessons learned and potential policy implications. These serve to contextualise and reinforce the more normative cross-study analysis that has been presented in the earlier sections of this report.

Both the cross-study analysis and the individual case studies have been considered in developing the overall conclusions and recommendations that are presented in full at the start of this report and are summarised at the end. 


\section{Acclimaterra, a study of climate change and its impacts in the New Aquitaine Region} [http://www.acclimaterra.fr/]

- Main Institutions: Sorbonne University, Paris, France

- Disciplines involved: Physics; biochemistry; oceanography; meteorology and climatology; economy; law; political study; social study.

- Societal partners: Regional and local authorities; NGOs; citizens.

- Funding and timing: EUR 100K/year (9 years). Main funding from the New Aquitaine local government.

Summary: Acclimaterra gathers scientific evidence on how climate change may affect key regional assets in a variety of domains (agriculture, fisheries, urban areas, littoral areas, mountains, etc.). It examines the direct and indirect consequences of these impacts (e.g., on economics, biodiversity, energy mix). Its aim is to propose specific adaptation actions to the regional government, while also identifying mitigation opportunities. In so doing it carries out dialogues with key actors in the region and develops outreach activities.

The origins of this project go back to 2014 when, in response to a request from the regional authority, a group of scientists from different disciplines came together to do a regional integrated science assessment similar to that conducted globally by the Inter-Governmental Panel on Climate Change (IPCC). This led to extensive dialogue with local stakeholders and $2^{\text {nd }}$ integrated assessment report was commissioned and published in 2018. The framing and development process for this $2^{\text {nd }}$ report involved active engagement with local social and economic actors. It was drafted by a core group of $\sim 20$ scientists with contributions from $\sim 300$ more experts from academia and non-governmental organisations. Publication was followed by an intense outreach effort.

The project implemented two parallel processes to incorporate diverse academic and stakeholder perspectives. The first was a dialogue within the academic domain, with progressive integration of science-oriented NGOs. The second was an outreach and dialogue process with civil society that included five meetings in different cities that helped frame the $2^{\text {nd }}$ report and an ongoing process of engagement with citizens, schools and other stakeholders in different towns and cities to discuss the report's findings. This engagement process has included the development of a 'climate train' travelling exhibition.

Acclimaterra is associated with almost all decisions being taken by the regional authority about climate change which is one indication of its impact. More broadly it has promoted an informed dialogue amongst different regional actors and contributed to education at different levels. Unfortunately, the main publications addressed to decision-makers are in French, which has not allowed for communication to the international scientific community.

\section{Lessons learned:}

- The project worked because there was a strong scientific motivation - to identify missing links and areas in scientific knowledge - as well as a clear policy demand from the local government.

- Many young researchers can be easily motivated to take part in outreach events and exhibitions.

- Locally targeted TDR can produce important learning experiences and knowledge of much wider relevance but language can be a barrier to dissemination.

- High-level scientific publications have been hindered by the local dimension of the study and by the fact that all initial materials were in French language.

Policy implications: Integrated scientific assessments can be enhanced by using a TD approach particularly where the aim is to translate the outcomes into local solutions. 
2. Agrophotovoltaics $\quad-\quad$ Resource-Efficient Land Use (APV-RESOLA) [https://www.ise.fraunhofer.de/en/research-projects/apv-resola.html]

- Main Research Institutions: Karlsruhe Institute of Technology; Fraunhofer Institute for Solar Energy Systems (ISE); University of Hohenheim.

- Disciplines involved: Agriculture; environment; biodiversity; techno-economics; and social sciences.

- Practice partners and stakeholder: Farmers (Hofgemeinschaft Heggelbach); renewable energy developer (BayWa r.e., EWS Vertriebs $\mathrm{GmbH}$ ); regional federation (Regionalverband Bodensee-Oberschwaben); local community (Herdwangen-Schönach).

- Funding and timing: EUR 223K (2015-2019). Main funding from Ministry for Research and Education

Summary: A main objective of this research project was the co-design of a societally acceptable and feasible technological innovation in the context of increasing land use competition. Agrophotovoltaics (APV) is a technology that combines power production with photovoltaics and agricultural food production by using high-fixed PV modules. APV is a technological response to the food versus energy debate that addresses different societal challenges, including the energy transition, climate change, and land-use efficiency. Power supply by open space photovoltaics (PV) requires large areas and thus increases the demand for limited agricultural land. Double harvesting with APV can potentially reduce the competition for land between agriculture and the energy industry.

This inter- and transdisciplinary project aimed to integrate non-academic stakeholders and actors in the process of co-developing the technology and identifying conditions for the design and implementation of APV, which meet the criterion of acceptability as well as the needs of policymakers, service providers and technology developers. With different formats and methods of social sciences, such as guided in-depth interviews, surveys and citizen and stakeholder workshops members from different stakeholder groups as well as citizens were integrated into the research concept to combine academic and non-academic perspectives. Participants in the citizen workshops were selected to ensure diversity in terms of age, gender, education, profession, political interests, etc. The requirements and recommendations from the citizen's perspective were analysed and discussed in a stakeholder workshop that included representatives from key stakeholder groups, such as decision-makers from administration, politics and economics, farmers association and local tourists association, as well as representatives from nature conservation. Main findings from these workshops were communicated to the technology developers and providers, who in turn were asked to respond to arguments and recommendations from the stakeholders.

The main challenge in the research project was to overcome the concerns of technology developers that social science could harm their project by identifying negative consequences, and thereby promoting resistance to the technology and the pilot plant. These fears were built on past negative experience of local public resistance to biogas plants and wind parks in the region.

\section{Lessons learned:}

- Citizens and stakeholder should be involved early during the development of technologies that may affect their local environment and quality of life.

- The relationship between research-based consultation and decision-making needs to be clear and transparent if trust is to be built and maintained among different stakeholders.

- It is important to create structures and build expertise that support TDR, as ITAS has done.

Policy implications: Governments, funders and universities should commit to supporting transdisciplinary approaches in technology development and assessment. This requires capacity building and new framework conditions for allocating funding. 


\section{ASU Decision Center for a Desert City (DCDC) [https://sustainability.asu.edu/dcde/]}

- Main Institutions: Arizona State University.

- Disciplines involved: decision science; policy studies; geography; hydrology; life science; economics; anthropology; computer science; urban planning; public administration.

- Societal partners: Local governments; environmental organisations; farmers; museums and schools.

- Funding and timing: 17M EUR (2004-) in total direct investment via the National Science Foundation (NSF), supplemented by $\sim 18 \mathrm{M}$ EUR in additional leveraged awards from NSF, NASA, NOAA and other sources.

Summary: The mission of the DCDC is to develop a transdisciplinary network of scientists, students, and stakeholders cooperatively producing transformational solutions to inform evidencesupported strategies for transitions towards sustainable water management in the Colorado river basin.

DCDC was established in 2004 with an investment from NSF through their Decision Making Under Uncertainty (DMUU) program. The Centre brings together a transdisciplinary team of social, behavioural, economic, and sustainability scientists working in close collaboration with stakeholders. A diverse group of undergraduate, graduate and postdoctoral scholars are educated and trained with a focus on key competencies in sustainability through real-world sustainability research and education experiences. The project builds on and strengthens networks of scientists and decision-makers that improve the relevance of scientific knowledge for policy and foster learning across diverse perspectives. A variety of formal and informal approaches are employed to ensure that non-academic perspectives are integrated into project design, implementation and evaluation. This includes science-policy workshops, collaborative (TDR) research and water/climate briefings. An External Advisory Committee includes representation from key decision-making institutions.

Early career researchers can face unique risks when participating in transdisciplinary projects, related to the length of time to publication and perceptions that use-inspired research is less rigorous or scientifically impactful than basic research. To address this challenge, the centre provides specialised training and post-doctoral research mentorship programs. All postdocs are required to submit an Individual Development Plan, as well as participating in regular mentorship meetings and evaluations. The Centre has worked also with university administration, as part of a larger university-wide effort, to reform promotion and tenure review procedures to provide adequate recognition for transdisciplinary research, and research that is focused on positive societal impact in addition to contributing to knowledge advancement. Indeed, conducting "Use Inspired Research" is one of the Eight Design Aspirations that guide the university.

\section{Lessons learned:}

- Specific strategies are needed to overcome lack of awareness of problems, including insufficient framing and unbalanced ownership of projects. Pilot studies can help identify and resolve these problems.

- It can be challenging to identify adequate funds to support broad stakeholder engagement through conventional science grants. Joint fundraising with stakeholders is one solution.

- Formal organisational structures to support collaboration (i.e., boundary-spanning organisations), as well as informal structures (i.e., social norms), are essential.

- Significant investment has been required in data infrastructure to address the challenge of integrating data across social/behavioural sciences with physical sciences and engineering.

Policy implications: Government and public sector organisations are important stakeholders in many TDR projects. Governments can provide incentives and time to support the public sector in participating in transdisciplinary collaborations and in making in-kind contributions of data and knowledge. 


\section{4. 'CAMINOLARGO' (Longroad), Colombia [https://caminolargo.co]}

- Main Institutions: Universidad El Bosque; Archives of Traditional Music, Indiana University; Fundación Instituto Folclórico Colombiano de Delia Zapata Olivella; El Palenque de Delia; Estudios Audiovisión.

- Disciplines involved: traditional music; ethnomusicology; architecture/territory studies; creative/cultural industries; sound engineering; musical production; sound documentaries; graphic and industrial design; law.

- Societal partners: Independent music producers and musicians.

- Funding and timing: EUR 9.7K (2018-2019).

Summary: The 'Caminolargo' project aims to pass on Maroon musical traditions to future generations - in particular, the music of Juan Lara as interpreted by Los Gaiteros de San Jacinto. This involved the recovery and understanding of cultural heritage in the form of music for pipers and its translation from a period when it was distributed directly from player to listener without any intermediaries to the modern era where cultural industries and information and communication technologies enable both the appropriation and the wide dissemination of music.

The project traces the history of the mixed-blood, 'heritageable' music of the 'palenques', where Maroon Afro-Americans lived together with Native-Amerindians on the Colombian Caribbean Coast for 200 years. It tells the story of Delia Zapata, folk-dance choreographer, who accompanied ethnomusicologist George List (Indiana University-ATM) during fieldwork (1964-1968). In San Jacinto (Montes de Maria), List recorded the testimony and pipe music of Los Gaiteros de San Jacinto (1G). List's archives rested at IU-ATM for 60 years until digital copies repatriated to Colombia in 2012 by ethno-musicologist J. Sebastian Rojas were re-appropriated by Los Gaiteros de San Jacinto (4G) in 2018.

The project concretizes a historical, technological innovation process in the form of a hybrid product-a CD/art book special edition-for collectors and archives, and digitally, through Internet platforms - complex products of the intersection of value chains and creative ecosystems in the music and publishing industries). Audiovisión studios (Bogotá) engineered a digital edition of List's archives in documentary format. 'Caminolargo' received a Global Music Awards Gold Medal (2019).

\section{Lessons learned:}

The transdisciplinary approach helped to capture Maroon culture through a complex creation 'triad' involving cultural industries, traditional creation, and arts-based research.

Policy Implications: TDR can play a role in the recovery, preservation and appropriate promotion of Cultural heritage, with arts and humanities having an important contribution to make. 
5. Climate Change and Sea Level Rise in the Anthropocene: Challenges for International Law in the 21st Century [https://www.fni.no/projects/climate-change-and-sea-level-rise-inthe-anthropocene-challenges-for-international-law-in-the-21st-century]

- Main Institutions: Fridtjof Nansen Institute

- Disciplines involved: International Law, Geological sciences

- Societal partners: The International Law Association (ILA), media, filmmakers, artists, cultural organizations, private organizations and inter-governmental bodies

- Funding and timing: EUR 782K (2014-2019). Main funding from the Research Council of Norway.

Summary: The overall objective of this project was to provide a comprehensive study of potential international law responses to scientific projections of sea-level rise. Changes resulting from sealevel rise will cause territorial changes, and may consequently question the agreed maritime boundaries and even the survival of some island states, with implications for migration. This will require a profound re-examination of some currently-accepted perspectives of international law. This work started as an interdisciplinary research activity, but it evolved into a truly transdisciplinary project.

There were pre-existing relationships between several project members in the international Anthropocene Working Group (AWG, under the aegis of the International Union of Geological Sciences) and several members of the ILA Committee on International Law and Sea Level Rise. The Principal Investigator- was involved in both AWG and ILA and this facilitated mutual communication between those two bodies. Additional aspects of transdisciplinary cooperation were developed, during a series of informal meetings and formal events that were organised by academic and non-academic partners, during the course of the project

The project had tangible societal impacts in different spheres. For instance, when the United Nations International Law Commission (ILC) included of the topic on Sea-level rise in its long-term programme of work, the focus was on those areas originally defined in the AWG-ILA work. Impacts of the project were also recognised when the Fridtjof Nansen Institute won the UK Prospect Award as the Best European Think Tank in the field of Energy, Environment and Science in three successive years from 2017 to 2019.

Project results were disseminated through media, including newspapers and presentation of project findings through documentaries, such as the "Anthropocene". This film has been shown at over 30 festivals worldwide. There has also been extensive dissemination of the project results through cultural and art institutions and events.

\section{Lessons learned:}

- Pre-existing relations with non-academic stakeholders, that may even depend on a single individual, can be critical to developing a TDR project.

- A TDR approach can increase the dissemination and impact of project results by providing broader access to media (e.g., newspapers and television/cinema) or cultural and art institutions (e.g., museums) which have a stake in the project outcomes.

- Established international associations/networks can provide an important anchor for transdisciplinary research that addresses global issues.

Policy implications: Research funders can promote transdisciplinary research by building on existing interdisciplinary activities, addressing problems that can benefit from including other stakeholders. 


\section{The Centre for Research-based Innovation in Sustainable fish capture and Processing technology (CRISP) [https://www.uib.no/en/research/75371/centre-research-based- innovation-sustainable-fishing-and-pre-processing-technology]}

- Main Institutions: Institute of Marine Research (IMR)

- Disciplines involved: led by marine acoustics, fishing technology, IMR is an interdisciplinary institute

- Societal partners: Manufacturers of fishing equipment, Norwegian Fishermen's Sales Association for Pelagic Fish and the Norwegian Fishermen's Sales Organization

- Funding and timing: EUR 24K (2011-2019). Main funding source from the Research Council of Norway and private companies.

Summary: CRISP was funded as a Centre for Research-based Innovation (CRI). The main intention of CRIs is to create or strengthen Norwegian research groups that cooperate closely with prominent innovation communities. The scheme is intended to improve Norway's industrial competitiveness and to support Norway's participation in strong international research networks. Fisheries technology is in a field where both the Norwegian industry and research institutions have strong traditions for innovation and cooperation, and it was anticipated that the partners would strongly benefit from joining a CRI.

The main objective of this project was to develop "smart technologies" which may lead to responsible fisheries and at the same time, improve the profitability of the fishing fleet and supporting industries. Some of the challenges in this project are to develop instruments to identify species and sizes of fish in the sea, to design trawls that minimise the environmental impact on bottom habitats, and to analyse the economic benefits to the fishing industry resulting from new technologies developed in this project.

There had been a long history of cooperation between most of the industry and research partners in CRISP. The research and industry partners selected the research themes in cooperation. The ideas for innovations were mainly launched by the industry partners, while the research teams added to the theoretical basis and field-tested the products under development. From a research capacity perspective it was notable that many students involved with this project are now employed in the fisheries sector, either in industry or academia. Although men traditionally dominate this sector, half of these students are female.

One major challenge in this programme was that there is a fundamental difference in the research partners' need for the publishing of their work to build a scientific career and the industry partners' need for confidentiality to protect their business ideas.

\section{Lessons learned:}

- The industry tends to protect data and information. On the other hand, researchers need to publish the results of their projects. This fundamental gap in their incentives may create conflict during or after TDR projects.

- Students who work on TDR projects can gain experience of working with the private sector (and other stakeholders) which can help them develop transferable skills. This can provide an entry to different career paths beyond academic research.

Policy implications: The research funders and institutions need to adjust their evaluation systems to value not only academic publications but also research-based innovation activities. 


\section{CuveWaters [http://www.cuvewaters.net]}

- Main Institutions: ISOE—Institute for Social-Ecological Research.

- Disciplines involved: Social sciences, civil engineering, urban water management,

- Societal partners: Water reclamation company; ministries (urban and rural development, water, agriculture, and forestry); regional and town council; traditional authorities; citizens and NGO; Desert Research Foundation of Namibia; German Corporation for International Cooperation (GIZ); German Federal Institute for Geosciences and Natural Resources (BGR).

- Funding and timing: No budgetary information (2006 - 2015). Main funding from German Federal Ministry of Education and Research.

Summary: Almost half the Namibian population lives in the Cuvelai-Estosha basin, an area characterised by climatic extremes, with droughts and floods alternating seasonally. This project aimed to support and improve Integrated Water Resources Management (IWRM) in the northern Namibian Cuvelai-Etosha Basin region. This required cooperation with local people as well as with private sector implementation partners, town and regional council, governmental institutions and traditional authorities.

The preliminary phase of the project was critical to analysing needs and getting to know the main stakeholders, other relevant institutions and formal and informal decision-making processes. The first phase, in Germany, featured a project structure linking ISOE-responsible for coordinating the project, social science research and the TDR approach - with various partners in the Technical University of Darmstadt and German companies, who led the construction and technological implementation options. Needs were initially determined through a survey of non-academic stakeholders, communicated to technicians/engineers and tested in the community. This participatory-adaptive demand-response procedure required significant effort but was of great importance.

The crucial feature of this project is that the local population accompanies and influences the design and realisation of technologies. Technical implementation is discussed with local residents and adapted accordingly. Moreover, engineering innovations are always coupled with capacity development. As such, local residents are trained in construction, maintenance and operation of the facilities. This project developed concepts for good governance and to support institutional processes, while investigating the underlying socio-ecological framework.

\section{Lessons learned:}

- Exploration of demand and requirements from potential users was a crucial first step for improving integrated water management strategies with new technologies.

- Building trust among local stakeholders was essential and this required a lot of effort with many meetings with the local partners and different institutions (town/regional councils, ministries and traditional authorities).

- Technical innovations need to be combined with social innovations for being sustainable.

Policy implications: Training for local partners is often important to ensure that the long term benefits transdisciplinary projects are realised and sustained. This requires support for capacity building embedded within TDR and for long-term follow up. 


\section{Food4Sustainability [http://www.food4sustainability.be]}

- Main Institutions: Université catholique de Louvain (UCLouvain), Université libre de Bruxelles (ULB), Katholieke Universiteit Leuven (KU Leuven)

- Disciplines involved: economics; policy science; business; philosophy; agronomy; Social Science and Humanities.

- Societal partners: stakeholders related to food supply chain, urban gardening, cooperative/social economy, catering, labelling, local currency and social financing.

- Funding and timing: EUR 750K (2014-2018). Main funding from Belgian Federal Science Policy Office

Summary: The provision of agricultural inputs and the production, packaging, processing, transport, and distribution of food contribute $19-29 \%$ of global anthropogenic greenhouse gas emissions, exerting significant pressure on natural resources - especially water, nitrogen, phosphate, and arable land. Reforming food systems is thus essential for a transition towards a low-carbon, resource-efficient society. This project examined potential transformation pathways, both in mainstream food systems that rely on large processors and retailers and in alternative food systems that have typically emerged in a bottom-up way, often through local and citizen-based initiatives. Challenges were identified in the project proposal, but precise themes resulted from co-design in the first and third years of the project.

The overall project direction was managed through in-person and virtual meetings with all project researchers and PIs of the various universities. To integrate across disciplines, the team implemented workshops and joint publications. This project relied on extensive semi-structured interviews and workshops with societal actors to identify potentially effective policy innovations, accounting for the values and beliefs of stakeholders in the various food systems. Non-academic participants were selected through systematic mapping of actors in the alternative food networks (urban gardens, collective food buying groups, etc.) and through workshops. Non-academic participants were all involved in co-design of research questions, with workshops being held at regular intervals.

Adopting a transdisciplinary approach allowed the team to develop a high-level, integrated understanding of problem domains, which required both knowledge from different disciplines and non-academic inputs and expertise.

\section{Lessons learned:}

- The main challenge was to adjust scientific protocols to varying access rights to data. For alternative food networks, a combination of in-depth case study research and large-scale comparative assessment through surveys - the preferred scientific approach — was possible. However, it was not feasible when dealing with the private sector, given the complexity of producing confidentiality agreements.

- To be successful, a transdisciplinary research project requires a true co-construction process that encompasses three dimensions: co-construction of the research question, the selection of methodologies and definition of the societal objectives in the problem field.

Policy implications: Governments can develop dedicated funding and evaluation mechanisms and establish centres of expertise in TDR. Universities/research institutions can take a lead in building capacity for TDR, including support for training and networks. 


\section{Frugal Innovations and Responsible Entrepreneurship: Case Studies in the Water and Health Sectors in East Africa [https://www.cfia.nl/home]}

- Main Institutions: Delft University of Technology; Erasmus University Rotterdam; University of Nairobi.

- Disciplines involved: Economics; engineering; ethics; medical anthropology; development research; philosophy; entrepreneurship.

- Societal partners: Electronics company (Philips); water treatment solution company (Hatenboer); drinking water company (OASEN); NGO.

- Funding and timing: EUR 507K (2015-2019); Main funding from Dutch Research Council (NWO).

Summary: This project explored new inclusive business models for Dutch companies to improve their performance in commercialising frugal innovations in developing countries. Technical design phases of the innovation development cycle were integrated with ethical and development considerations. Results should help entrepreneurs understand how, when and why to integrate ethical and developmental considerations in technological development processes.

The project originated in an existing Dutch academic network in response to a call from the Dutch funding agency NWO, with partners selected based on familiarity and earlier collaboration experience. Academic partners in East Africa were selected to meet the needs of the research project, although the inclusion of partners from the region of interest was also a requirement of the funding programme. In general, academic partners provided theory, while private sector partners provided empirical data. Private sector partners also contributed about one-quarter of total funding.

The transdisciplinary engagement occurred most prominently at annual meetings, but frequent additional contacts were made. Whereas the transdisciplinary approach was initially designed to meet the requirements of the funding call, it became clear over the course of the project that it added substantial value. For example, understanding the roles and actions of various partners with respect to frugal innovation led to important insights about equity-related consequences of certain interventions. Collaboration with non-academic partners allowed for incorporation of real-world cases, data and practical experience. For industry, added value consisted in part in learning how to experiment with an idea in collaboration with academics. The inclusion of ethics at an early stage was seen as having significant value. Challenges included the tendency for private sector partners to be protective of proprietary data. Important project outputs included scientific findings in journal articles, annual reports, the project website, and a video.

\section{Lessons learned:}

- Lack of institutional arrangements and support pose significant challenges for TDR

- Both academic and non-academic partners must benefit from TDR, for it to be successful. Template agreements that harmonize expectations and responsibilities between different actors can help

- Awareness of direct competition among private sector partners can be important

Policy implications: Despite a trend towards more TDR including support from funders, institutional mechanisms to support it are often not in place and this can be more of a challenge the more partners that are engaged. 


\section{Governing risk society (GOVRISK) [https://blogg.hioa.no/govrisk/]}

- Main Institutions: Norwegian Institute for Urban and Regional Research, Oslo Metropolitan University; Norwegian Institute for Water Research; Department of Business Administration, Technology and Social Sciences, Luleå University of Technology; University of Gothenburg; InterSus.

- Disciplines involved: Political science; policy; law; environmental science; geoscience; ecology.

- Societal partners: Norwegian Water Resources and Energy Directorate.

- Funding and timing: EUR 950K (2014-2018). Main funding from Research Council of Norway

Summary: This project aimed to provide new knowledge on how to increase local adaptive capacity to the negative impacts of climate change, including flooding and landslides. The focus was on the role of planning and learning networks.

Expected impacts were: A) to increase insights into how legal, financial and institutional instruments hinder or stimulate local climate change adaptation; B) to gain new knowledge on how planning can be used as a mechanism to increase cross-sectoral and multi-level coordination of climate adaptation efforts by public and private actors; C) to increase understanding of how learning networks can function as arenas for interpretation, contributing to a comprehensive proactive approach to local climate change adaptation; D) to contribute to development of new models for cross-sector and multi-level coordination.

Teams were based in Norway, Sweden and Germany. Project meetings (most frequently among the Norwegian team, but occasionally including all teams) constituted the primary mechanism for integration across disciplines and between academic and non-academic project participants. A project leader/coordinator followed-up with all project participants every month. Principal investigators reported on progress to the Norwegian Research Council every year.

The main challenge for the team was finding sufficient time to fully present different perspectives and learn from each other through discussion. Joint authorship of articles was also challenging and required identification of unfamiliar cross-disciplinary journals in which the work could be published. Nevertheless, the work has been published in national and international journals and the findings have served as input to the Norwegian Environment Agency in developing new policy instruments.

\section{Lessons learned:}

- Management of TDR projects can be complex and regular whole-team project meetings were important for cross- and transdisciplinary learning.

Policy implications: Governments and research funders can stimulate TDR projects by designing targeted calls for this type of research. 


\section{Strengthening international Collaboration for Capitalising on Cost-effective and Life- saving Commodities (i4C) [https://www.fhi.no/en/qk/international/global-health/bilateral- collaboration/i4c/]}

- Main Institutions: Norwegian Institute of Public Health; University of Oslo; York University, UK.

- Disciplines involved: Art; political science; interdisciplinary humanities; medicine.

- Societal partners: Joint United Nations Programme on HIV/AIDS(UNAIDS); Gavi, the Vaccine Alliance (GAVI); Mali Ministry of Health and Social Affairs; Republic of Namibia.

- Funding and timing: EUR 2.4M (2014-2019). Main funding from Research Council of Norway.

Summary: This project aimed to evaluate potential policy interventions to support global health institutions in scaling up access to, and innovation for, cost-effective and life-saving commodities. For example, one sub-project explored the role of art in advocacy for evidence-based decisionmaking. In this case, a trans-disciplinary approach was used both to design and evaluate the impact of an art exhibition.

The art exhibition project brought together a range of academics, including professors and students from policy studies, global health, studio art, art history, interdisciplinary humanities, law, and digital humanities. And it engaged with individual artists and senior administrative staff at UNAIDS. Over three years, three workshops were held with all participants to discuss plans for the art exhibition. Monthly meetings were convened for the core research team, which included the two principle investigators and lead artist. At the outset, the differences between expectations for outputs, including publishing norms in different disciplines, were discussed at length. It was agreed that the work be published in both health science and humanities journals that would be recognized by individual researcher's peers groups.

The project created an evidence-based art exhibit that was designed to influence decision-making processes. Though this impact was difficult to measure, other outcomes were taken as measures of success. For example, commentaries on the art exhibition were given by high-level policymakers and influencers, and it was positively reviewed in both The Lancet and Canadian Art, two journals with different disciplinary focus. In this sense the project could be considered a success and it is interesting to reflect that when the main project funding proposal was originally evaluated the art exhibition plan was criticised due to its transdisciplinary nature and 'non- academic' outputs. The funding for this part of the overall project was reduced and additional funding had to be secured from other sources.

\section{Lessons learned:}

- TDR requires sufficient time for participants to get to know and truly understand one another and appreciate each other's disciplinary knowledge and background.

- Because universities are structured to recognise outputs that adhere to disciplinary norms, there is a challenge in translating transdisciplinary outcomes into accountability mechanisms, so as to give proper credit to students and faculty and thereby support their career advancement.

Policy implications: Universities and research institutions need to provide academics with the flexibility to take on, or participate in, transdisciplinary projects. Funding agencies need to adapt their traditional peer- review processes to accommodate transdisciplinary research and attach due value to outputs other than academic publications. 


\section{Innovating Spatial Development Planning by Differentiating Land Ownership and Governance (INDIGO) [http://theindigoproject.be]}

- Main Institutions: KU Leuven; Universiteit Antwerpen; Harokopio University; OMGEVING cvba (BE) (private consultancy).

- Disciplines involved: Spatial development analysis and planning; territorial development; geography; legal studies; environmental sociology; political economy.

- Societal partners: Consulting offices in spatial planning; government agencies in planning, environment, rural development; organisations of landowners; professional federations of planners and notaries; nature conservation organisations; farmers; housing providers.

- Funding and timing: EUR 2.2M (2015 - 2018). Main funding from Flemish Agency for Innovation by Science and Technology (IWT), now Flemish Agency for Innovation and Entrepreneurship (VLAIO).

Summary: INDIGO was a research project on territorial development, land ownership and governance of land use rights in Flanders (Belgium). It aimed to understand how land use rights are governed, land access is organised and landed commons are co-created and to contribute to the development of innovative forms of shared land use and valuation. The project particularly focused on the embeddedness of land access and commons in wider socio-economic and socio-political dynamics and the process of building landed commons.

This complex study involved multiple disciplines and stakeholders across different sites in Flanders and linked with parallel studies in other European countries. A layered management structure included a coordination team ( 3 persons), a core management team from 4 research partners (6 persons), a case study partner group ( 9 persons) and a stakeholder advisory group ( $\sim 30$ people).

Although letters of intent were written by all academic and stakeholder partners during proposal development, ensuring long-term commitment and engagement was challenging, as was the full inclusion of diverse (academic and stakeholder) perspectives. In addition to formal governance structures and workshops, continuing informal discussions were necessary. Various novel methods were also used, including provision of research funding for stakeholders and co-publication of a non-academic book. These efforts resulted in strong engagement of all stakeholders in developing the analytical framework and good involvement of researchers from different disciplines in conducting the case studies.

Stakeholder engagement takes time and resources beyond those normally required for research projects. In this case, a greater-than- $50 \%$ time increase was needed to accommodate the emergence of shared inter- and transdisciplinary frameworks, language, methodologies, etc.

\section{Lessons learned:}

- Sufficient time and resources for effective exchange among different disciplines and between researchers and stakeholders on all aspects of the research are important. This must start during proposal writing and continue throughout the project.

Policy implications: Government can support TDR by providing resources for long-term research Funding agencies need to provide a strong framework of requirements on the nature of the research while allowing maximum flexibility for meeting these requirements. Universities and research institutions can create frameworks, e.g. for allocating funds and performance evaluation, that are more open to unconventional ideas and non-traditional approaches. 


\section{International Research Institute of Disaster Science (IRIDeS)} [http://irides.tohoku.ac.jp/eng/index.html]

- Main Institution: Tohoku University

- Disciplines involved: Tsunami engineering; earth science; civil engineering; history; art history; disaster medicine; clinical psychology; economics; public policy.

- Societal partners: Sendai city; Kesennuma city.

- Funding and timing: 84M EUR (2012-2020). Main funding from various sources, including university grants from government, competitive grant-in-aid for research, contracts, donations etc.

Summary: IRIDeS was established to create a new approach to disaster mitigation research, synthesizing lessons from the 2011 Great East Japan (Tohoku) Earthquake and Tsunami with the findings from different research fields related to disaster research and societal resilience. Its aim is to exploit learning for management of future disasters and support social systems to respond promptly, sensibly and effectively to natural disasters. The founding Director was a historian and his successor and current director is from Tsunami engineering, whilst the President of the host University, Tohoku, was a medical doctor. This nicely illustrates the breadth of disciplines that IRIDeS brings together. The Institute also has extensive links with other stakeholders, was actively involved in organising the UN World Conference on Disaster Risk Reduction in 2105 and coorganises the World BOSAI Forum biennially that brings together researchers, policy makers and other actors with an interest in disaster risk reduction and mitigation.

Action-oriented research is conducted under several themes, ranging from the physics of global scale natural disasters to disaster medicine and building disaster resilient societies. The institute also hosts the Global Centre for Disaster Statistics, with UNDP, JICA and a private company, Fujitsu, -being responsible for the construction of the database. Cooperation across various sectors is promoted through meetings, information-sharing, regular stakeholder fora, and periodic study sessions with the Regional Development Bureau of the Ministry of Land, Infrastructure, Transport and Tourism. Trusted relationships with a variety of public and private sector stakeholders have been built through cooperation in the development of disaster management plans. Broader societal engagement includes the participation of local volunteers in the rescue of historical documents.

Up until 2014, the Institute was distributed with affiliated researchers being spread across the University campus. Then a shared physical base was established with research facilities and support for public relations and outreach. Researchers are evaluated not only on via the traditional quantitative university system but also on their contribution to society. In order to encourage participation of early career researchers, exchange workshops are held and a new evaluation and reward system was introduced in 2018.

A variety of outputs are produced by the institute including: publication of scientific findings in journal articles, development of a new interdisciplinary academic journal - Progress in Disaster Research (Elsevier), workshops and conferences, the project website, an archive of the earthquake disasters, and disaster management plans for local governments and companies.

\section{Lessons learned:}

- Co-locating researchers from different disciplines in the same place /area improves exchange of ideas and collaboration and can provide a focus for TDR projects.

- Arts and humanities can provide important perspectives and methods for understanding and communicating complex societal issues in TDR projects.

Policy implications: Physical interdisciplinary centres or institutes embedded within traditional universities can provide a focus for promoting and accelerating TDR. 


\section{Japan-ASEAN Science, Technology and Innovation Platform (CHIRP/JASTIP)/ Collaboration Hubs for International Research Programme \\ [http://jastip.org/en/about/mission/]}

- Main Institutions: Kyoto University.

- Disciplines involved: Energy and material sciences; forestry; biotechnology; natural disaster-related sciences; anthropology; humanities and social science.

- Societal partners: Inter-governmental organization; national and local government; private sector; civil society (e.g., grassroots associations and local communities).

- Funding and timing: EUR 4M (2015-2020). Main funding from Japan Science and Technology Agency (JST).

Summary: JASTIP aims to help address social and environmental challenges in the ASEAN region by fostering STI collaboration between Japan and ASEAN countries. It is a collaborative platform that focuses on priorities agreed upon by ASEAN Member States. As mono-disciplinary approaches often fail to disentangle complicated and intertwined real-world problems, an inter- and transdisciplinary approach is the norm for JASTIP's projects.

JASTIP is hosted by Kyoto University which has a long history of research collaboration across South east Asia, including substantial funding through national Centres of Excellence programmes that were the precursors to JASTIP. As well as acting as a focus for connecting different disciplines and actors across the universities in Japan and ASEAN, the platform has 2 main pillars:

- Three joint laboratories in the fields of Energy and the Environment, Bio-resources and Biodiversity and Disaster Prevention, located in Thailand Indonesia and Malaysia. These laboratories, act as regional hubs and have to secure their own core funding.

- JASTIP-Net, which acts as an incubator and provides seed-funding for new collaborative projects, covering ASEAN countries that do not host regional hubs.

The research carried out under these themes is solution focused and takes into account the loca context in which the solution is to be applied. Private companies are often important partners in implementing research activities but addressing local needs and requirements is the dominant driver. TDR approaches need to take into account of the diversity in political systems, economy, culture, geography and social setting. For example, in the case of a rural electrification project, the selection of an appropriate technological solution depends on the unique characteristics of each project site.

The outputs and impact of JASTIP projects extend beyond scientific publications and often can only be evaluated over the long-term. Proxy measures, including the extent of collaborations or demand for JASTIP services from countries and private companies, are used to provide some indication of performance. However, at the level of individual researchers, the emphasis on traditional research outputs can be a significant disincentive to engage in JASTIP projects. Commitment to TDR does not always lead to a successful career path in academia and even where senior academics engage in JASTIP projects they do not always encourage their students to do so.

\section{Lessons learned:}

- In trans-national projects, in particular, it is necessary to visit study sites and interact with local stakeholders to understand context and frame problems before proposing solutions.

- TDR projects may be too time-consuming to productively include early-career researchers, given their obligatory focus on producing academic outputs and securing stable academic posts.

- Successful TDR projects are supported by University Research Administrators and have dedicated coordinators who help to bridge among different disciplines and to ensure longterm commitment from non-academic participants.

Policy implications: Impact assessment of transdisciplinary projects needs to go beyond traditional academic research outputs and timescales.

Transnational funding mechanisms for TDR would greatly facilitate the development and implementation of sustainable solutions for complex societal challenges 


\section{Jigjiga University One Health Initiative (JOHI)}

- Main Institutions: Jigjiga University; Somali Regional State, Ethiopia; Armauer Hansen Research Institute, Ethiopia; Swiss Tropical and Public Health Institute.

- Disciplines involved: Human health; veterinary medicine; nutrition, water and sanitation; rangeland management.

- Societal partners: Pastoralist and agro-pastoralist communities in the Somali Region of Ethiopia; health and animal health care providers; regional and federal authorities, community leaders.

- Funding and timing: EUR 4.7M (2015-2025) from the Swiss Agency for Development and Cooperation, supplemented by a $60 \%$ matched contribution from other partners.

Summary: The health and wellbeing of mobile pastoralists and agro-pastoralists, and the animals that constitute an important part of their livelihood, can be improved through locally-adapted interventions in health care, nutrition, animal health, rangeland management, market access and food system transformation. To this end, research capacity a range of related fields has been built up at Jigjiga University by working in close collaboration with the Swiss Tropical and Public Health Institute. This truly inter- and transdisciplinary research programme engages with local communities, local, regional and federal authorities and scientists to co-produce transformational knowledge for locally-adapted interventions and policy recommendations. For example, pastoralists share their own soil classification system which is matched with satellite images.

The active participation of local communities, authorities and experts is crucial for development of locally-adapted interventions. Participatory transdisciplinary stakeholder meetings were critical at the outset of the project to contextualise and co-define the problems to be addressed. Similar meetings took place at least annually to jointly review and, where necessary, amend the research agenda, discuss results, plan interventions and review implementation progress. Projects have thereby fostered a high level of local ownership, both at the University of Jigjiga and among the communities and local authorities involved in the study. Capacity building both within the University and for non-academic partners will be critical in ensuring the longer-term usefulness, application and impact of the project. The projects was used to train a cohort of local young scientists and a new curriculum was developed at the University of Jigjiga to leverage the educational potential of the project.

The project has clearly demonstrated that novel forms of joint human/animal health surveillanceresponse have significant potential but such systems will need to be maintained and improved over the long-term.

\section{Lessons learned:}

- The adoption of a participatory, transdisciplinary from the outset is critical for creating strong ownership among different stakeholders.

- Capacity building will need to be an integral part of many TDR projects if the longer-term impacts are to be realised.

- High turnover among authorities and academic leadership can affect continuity. It is important to select partners who can ensure longer-term commitment from the institutions and stakeholder groups that they represent

Policy implications: In partnerships with less economically developed countries in particular, capacity building needs to be considered as an integral part of TDR projects. This requires long-term commitment and dedicated resources. 


\section{Living Agricultural Landscapes - farmers shaping diversity [http://lebendige- agrarlandschaften.de/]}

- Main Institutions: Leibniz Centre for Agricultural Landscape Research (ZALF); German farmers' association (DBV), Farming and Winery Association Rheinland-Nassau, Foundation for Westphalian Cultural Landscape, Foundation for Rhenish Cultivated Landscape

- Disciplines involved: Agriculture, social science, environmental science, ecosystem services.

- Societal partners: Farmers; winegrowers; German farmers' associations

- Funding and timing: EUR 3M (2014-2021), Main funding from Federal Agency for Nature Conservation (BfN) with funding from the Federal Ministry for the Environment, Nature Conservation and Nuclear Safety (BMU); Landwirtschaftliche Rentenbank

Summary: The primary objective of this cooperation project is to evaluate agricultural methods that protect and promote biodiversity and ecosystem services and to assess farmers' attitudes towards nature protection measures incorporated into regular farming activity. In this context, it also aims to develop advanced training programs for farmers. Starting in three model regions, production-integrated nature conservation measures are being adapted and implemented by farmers and winegrowers working closely with consultants. Successful measures will be transferred to other regions of Germany.

ZALF had previously focused on interdisciplinary research and agricultural databases. However, they recognised the need to transform scientific knowledge into practical solutions, necessitating a transdisciplinary approach. The farmers' association, as the project coordinator with direct links to farmers and winegrowers, ensures practical relevance and thus increases the level of awareness of the measures and communicates the project results to political decision-makers.

The challenge of preserving and promoting biodiversity in the agricultural landscape requires a joint commitment from key actors in agriculture and nature conservation and strong political and societal support. At the outset, regional actors were wary of the scientists, as they thought that they would be carrying out a critical assessment. In practice, the scientists focused on observing and understanding processes in order to learn therefrom and improve practices. Once this was understood by regional actors, trust was established and the mutual learning that is inherent in TDR created a win-win situation.

A significant challenge for the researchers was to generate scientific outputs comparable to those produced in traditional non-TDR projects. Scientists are judged in large part on the number of publications, so a low publication output can be detrimental to research careers. TDR takes time and academic publications are but one of a number of main outputs. In general, academic evaluation processes act as a disincentive for TDR projects.

\section{Lessons learned:}

- TDR takes time.

- TDR requires a wide range of communication skills, adapted to different actors, in order to create a good basis for cooperation.

- It is important to build trust by sharing data and ensuring that results are transparent.

Policy implications: Research assessment and evaluation processes need to be adapted for TDR. Funding mechanisms need to make allowance for the extra time required to conduct TDR research. 


\section{MobilAir [https://mobilair.univ-grenoble-alpes.fr/]}

- Main Institutions: French National Centre for Scientific Research (CNRS); French National Institute of Health and Medical Research (INSERM).

- Disciplines involved: environmental economics; sociology; geography; planning; behavioural psychology; biology; health.

- Societal partners: Grenoble Metropolitan Authority, City of Grenoble; French Environment and Energy Management Agency (ADEME); and the Federation of Air Quality Monitoring Associations France (ATMO).

- Funding and timing: EUR 4M (2018-2021). Main funding from Université Grenoble Alpes and CNRS.

Summary: Urban atmospheric pollution is a major challenge for public health in both developed and developing countries. It causes approximately 48000 premature deaths annually in France and about one hundred in the metropolitan area of Grenoble. Via a transdisciplinary approach, MobilAir aims to identify precise measures to significantly reduce atmospheric pollution and associated damages in this city. Drawing on the considerable disciplinary diversity of the scientific community of the Grenoble-Alpes University, MobilAir adopts an integrated approach for Grenoble, a relevant pilot site for France as a whole. The collaboration across disciplines is facilitated by substantial institutional support in the form of Idex (Excellence Institute initiative) cross-disciplinary projects funding that has leveraged other resources. MobilAir aims to develop methods and instruments that can be replicated elsewhere in France and in other countries.

Demand from non-academic partners has been a key driving force since project inception. Project governance relies on three independent entities: a Steering Committee, an International Scientific Advisory Board and a Decision-makers Committee-non-academic partners are strongly represented in the latter. A Stakeholders Committee is tasked with dissemination of results and feedback to and from civil society. Issues related to interactions with public decision-makers are addressed by the Decision-Makers Committee which meets annually, and is composed of the president of the Grenoble metropolitan area, the three Vice-Presidents in respectively in charge of the environment, mobility and research, representatives of the city of Grenoble and the French Environment and Energy Management Agency. In accordance with MobilAir's innovative approach, these interactions are central to project implementation.

The activities include the elaboration, implementation and assessment of a programme intervention aimed at promoting behavioural change and the use of more active and collective transport modes. This includes plans for a randomised controlled trial involving several hundred people. The intervention is highly inter-disciplinary and multiple quantitative and qualitative outcome measures will be collected.

\section{Lessons learned:}

- MobilAir took almost three years to set up from first meetings to the securing of main funding. During this time, researchers learned to interact and to understand one another's research questions through the lenses of their own disciplines. This experience illustrates the length of time required to set up such a transdisciplinary project.

- Core investment and support from the host institution has been critical in ensuring crossdisciplinary engagement and has led to contributions from other funders, although managing multiple funding sources has its own challenges.

- The constant implication of the policy-makers, from the start of the project, has allowed for a full integration of the public policy dimension in the different research.

- In terms of scientific practices, the challenge of data management may be easily underestimated when diverse data from multiple different sources need to be integrated.

- The strong dedication of all researchers to societal and environmental values has allowed for the coherence and success of the project.

Policy implications: Funders, research institutes and Universities need to work together to develop the structural conditions and long-term support for transdisciplinary research. 


\section{Mobility Innovation project by Centre of Innovation (COI, Mobility)} [http://www.coi.nagoya-u.ac.jp/en]

- Main Institutions: Nagoya University; Toyota Motor Corporation.

- Disciplines involved: Mechanical engineering; information science; urban planning; human health; sociopsychology; law.

- Societal partners: Toyota Motor Corporation; Japan Ministry of Land, Infrastructure and Transport; Aichi Prefectural Government; Toyota City; Kasugai City; Nagoya City; Kota Town.

- Funding and timing: EUR 57M (2015-2019, extended to 2021); Main funding from Japan Science and Technology Agency (JST).

Summary: This project aimed to develop mobility technology to allow senior citizens in the ageing Japanese society to stay active and participate in their communities. The research plan emerged from discussions among Nagoya University, the Aichi Prefectural Government and Toyota Motor Corporation, and was then approved by the COI visionary team consisting of leaders in industry and academia. The visionary team visits the research centre annually to conduct project reviews.

Under the COI program, project leaders must have industrial experience. In this case, the leader was a manager at Toyota Motor Corporation with a concurrent position at Nagoya University. Within the project, several types of meetings were implemented for different management layers and to ensure the continuous engagement of various actors.

Toyota Motor Corporation is headquartered in Toyota City in Aichi prefecture. Local cities are heavily involved in the development of autonomous driving systems. The Aichi prefectural government maintains a one-stop service to authorise field testing of autonomous driving systems, with the participation of the prefectural police agency and a local office of the Ministry of Land, Infrastructure and Transport. The research team assigned a social implementation leader to liaise with these organisations.

A transdisciplinary approach was essential for this research project on development of practical mobility services for the elderly. Early in the project, "elderly wellbeing" was defined through a series of interviews with local elderly people. These interviews led the project to redefine its goal, shifting from full-scale to "slocal" (i.e., slow and local) automated driving. The new formulation focused on social implementation to fulfil local residents' actual needs. To date, the project has developed hardware and software for "slocal" autonomous driving and a walking assistance robot. Traditional research approaches would have struggled to grasp the true problems associated with social implementation.

\section{Lessons learned:}

- Developing and sharing a project vision with all participants is important and this vision needs to be re-examined continuously.

- The length of the project needs to be longer than the standard five years to allow for full problem definition, which is an ongoing and iterative process.

- Having academia researchers and non-academia researchers work in the same place (under one roof) was important for promoting collaboration.

Policy implications: Relevant authorities and research funders may need to be directly involved in project management to support it from a regulatory and monetary standpoint. 


\section{MontanAqua: Approaching water management in times of scarcity and climate change} [http://www.nfp61.ch/en/projects/project-montanaqua]

- Main Institutions: Universities of Bern; Lausanne and Fribourg, Switzerland.

- Disciplines involved: Geography; environmental science; hydrology; social science.

- Societal partners: Cantonal and Communal authorities of Valais and Crans-Montana, Switzerland; hydropower; viticulture; agriculture; environmental NGOs.

- Funding and timing: $400 \mathrm{~K}$ EUR (2010-2013). Main funding from Swiss National Science Foundation.

Summary: Availability and consumption of water are changing due to climate change and socioeconomic development, potentially leading to water distribution conflicts. The aim of this project was to develop sustainable water management strategies in cooperation with local stakeholders in the Crans-Montana-Sierre region in the Swiss Alps. To this end, the team applied a TDR approach to co-produce systemic models, desirable targets for intervention and transformative strategies. A plurality of critical factors discussed in water-related climate research are present in this region, e.g. water gradients, scarcity, conflicts over utilization, and accommodating these required a truly transdisciplinary approach

At the outset of the project, four different visions for regional development were co-developed with local stakeholders and it became clear from their subsequent quantification and modelling that socioeconomic factors would have a more impact on future water systems than climate change. This reality was critical in developing sustainability scenarios that were realistic and useful for informing real life decision-making on water management that takes into account multiple interests.

Transdisciplinary collaboration enabled this project to: i) grasp the complexity of the regional water situation and create a holistic understanding of sustainability problems and possible solutions; ii) recognise the contested nature of water sustainability among various interests and to facilitate dialogue on more sustainable water futures; iii) elaborate and discuss relevant, meaningful water management options for regional stakeholders. The longer term outcomes included the development of a local informal multi-actor 'knowledge network' that is able to engage constructively in decisions on water management

\section{Lessons learned:}

- Transdisciplinary processes can only succeed through de novo negotiation over cooperation and competition, in which social skills and open-mindedness are essential.

- Having a dedicated and skilled coordinator/facilitator who acted as an intermediary between different project participants and institutions was critical for the success of this work.

- The main ingredients for success are cooperation, clarity in roles and concepts, strong motivation, commitment and trust.

Policy implications: Whilst new scientific insights are an important output from TDR, key impacts are often in terms of societal changes, e.g. better decision-making and governance. These become apparent on a longer time scale and are more difficult to assess and evaluate than traditional science outputs like publications. New performance measures are needed for TDR. 
20. Participatory Value Evaluation of energy policies [https://www.nwomvi.nl/project/participatory-value-evaluation-new-assessment-model-promoting-socialacceptance-sustainable]

- Main Institutions: Delft University of Technology

- Disciplines involved: Economics; philosophy; ethics; behavioural econometrics; energy systems engineering

- Societal partners: Consulting companies (Quintel; Harmelink; Greenvis)

- Funding and timing: EUR 478K (2018-2021). Main funding from NWO, VolkerWessels, ABN AMRO, Enpuls, Greenvis, Waternet and Municipality of Amsterdam.

Summary: Various stakeholders in the Netherlands have recently set ambitious targets for the decarbonisation of energy systems. For instance, the alderman of Amsterdam promised that the energy system will be decarbonized by 2050; private bank ABN AMRO aims to improve its entire real estate portfolio by 2030, resulting in a $\mathrm{CO}_{2}$ emissions reduction of 2 megatons per year. However, currently available assessment models are inadequate for evaluating concrete sustainable energy policies to realise these ambitions. At the same time, stakeholders contend that conventional participation methods are likely inadequate to establish social acceptance for sustainable energy projects. Participatory Value Evaluation (PVE) is a promising assessment model which also comprises a concrete approach to amplify participation and thereby potentially increase social acceptance of sustainable energy projects.

All the disciplines involved in this project are, in principle, needed for the design of PVE. This is indeed challenging and requires compromises. For instance, in engagement across disciplines, materials and procedures must be useful to and comprehensible for all practitioners. This was an important consideration in organising a design workshop that was held with all practitioners to discuss a draft version of a new PVE.

Ultimately, this project expects to improve evaluations of the societal value of sustainable energy policies and to facilitate the mass participation of citizens in the design of energy policies.

\section{Lessons learned:}

- Divergent disciplinary expectations regarding publication and the differing expectations of academic institutes posed challenges in deciding how to proceed with the academic findings of this collaborative work. Most institutions are structured to produce and evaluate mono-disciplinary work. Researchers must provide extra justification for carrying out work that does not always generate academic outcomes.

- A substantial proportion of the principal investigator's effort goes toward coordination. Supervision of postdocs in TDR projects is different, as they are expected to have skills an average academic postdoc does not require, such as communication skills to engage non-academic partners.

Policy implications: Universities and funding agencies could better support the process of initiating and implementing TDR, including recognition of the value of facilitation and communication skills. 


\section{Precise Advanced Technologies and Health Systems for Underserved Populations (PATHS-UP) [https://pathsup.org/]}

- Main Institutions: Texas A\&M University (TAMU), University of California Los Angeles, Rice University, Houston, Florida International University, Miami.

- Disciplines involved: Biomedical; electrical; mechanical and industrial engineering; computer science; chemistry; materials science; medicine; health and kinesiology; community engagement; behavioural psychology.

- Societal partners: Patient; health care provider; caregiver; community health advocate; industry; insurance provider; private foundation; government agency.

- Funding and timing: 17.60 M EUR over 5 years (2017-) with a possible extension of 5 years leading to over EUR 31M. Main funding from Engineering Research Centers, National Science Foundation.

Summary: Over the last two decades, chronic diseases have emerged as the leading cause of morbidity and mortality in the US and globally. CVDs are now the leading cause of death worldwide, with cancer, pulmonary diseases, and diabetes close behind. Chronic diseases are particularly devastating in underserved communities in the USA, where they occur at a rate higher than the national average. This inter- and trans-disciplinary research centre aims to change the population health paradigm by developing point-of-care devices and systems, particularly for cardiovascular disease (CVD) and diabetes among underserved populations.

The researchers that contribute to the centre's activities are distributed across 4 research Universities and come from diverse disciplines. Collaboration across the sites is assured at the leadership level by having all sites represented on an Executive Committee, with leadership for specific projects being distributed. Overall the Centre includes 25 senior researchers, about 90 students, hundreds of people with diabetes or cardiovascular disease from the communities, and multiple health care providers, industrial partners, state agencies and regulatory authorities. The Centre makes a concerted effort to involve junior faculty, including the provision of seed funding afforded through industry partnership.

Health care providers, caregivers, and people from the underserved communities with diabetes or cardiovascular disease are engaged in developing monitoring devices through a participatory design process. They guide scientists and engineers in designing appropriate devices by specifying desired characteristics and offering practical observations regarding the functioning of such devices. In addition, people with diabetes or cardiovascular disease will be involved in performance studies of devices under development.

\section{Lessons learned:}

- The most important challenge is effective communication and building mutual respect among diverse cultures and disciplines.

- Translational research toward medical device development at the point-of-care should take into account user needs and the environment in which the devices are to be used in order to provide successful translation and integration that will allow for behaviour modification and overall improved health outcomes.

- In the health and medical device field, the designer must be mindful of the regulatory processes. In this case, the US Food and Drug Administration sits on the project's Industry/Practitioner Board to provide early feedback on the devices designed.

Policy implications: Universities/research institutions need to support faculty that want to write such larger programmatic grants by offering sabbaticals and release from other duties in order for them to have the time to make the connections, establish the grand challenge, and prepare a strong competitive proposal. TDR often involves large research teams, with contributions from a variety of disciplines and non-academic stakeholders, individual credit and reward mechanisms need to be adapted to reflect this. 


\section{PigSustain [https://gtr.ukri.org/projects?ref=BB\%2FN020790\%2F1]}

- Main Institutions: University of Leeds; University of Lincoln; London School of Hygiene \& Tropical Medicine; University of Reading, Animal and Plant Health Agency

- Disciplines involved: Systems modelling; Animal health and welfare; veterinary epidemiology; public health; environmental epidemiology; veterinary diagnostics; sociology; human geography; computer science; remote monitoring; economics.

- Societal partners: British Department for Environment, Food \& Rural Affairs (DEFRA); Food Standards Agency (FSA), Red Tractor, Agriculture and Horticulture Development Board (AHDB); pork producers/processors (Cranswick, Yorkwold, Elsham, Karro Food Group).

- Funding and timing: 2.4M EUR (2017-2021). Main funding from UK Research and Innovation (UKRI) and the Scottish Government.

Summary: The primary objective of this project was to improve understanding of the resilience of the UK pig industry in an international context. Currently there is not a robust system to quantify and forecast how the national pig industry will be impacted by future changes in intensification, climate, international trade and other external factors. Against this background, the aim is to develop a systems model alongside an AI-driven remote monitoring surveillance system that can be used to support complex decisions about disease prevention and control, international trade, climate change and consumer preferences.

There are five Work Packages (WPs) for specific research themes, and a sixth WP was designed for project coordination and integration. Each WP was designed to promote collaborative working. Formal WP Leader teleconferences were scheduled monthly with all disciplines present and providing input. The moderation of this management meeting rotated among WP leaders, with each presenting findings to the wider group. In addition, dedicated training sessions were put in place to enable transdisciplinary skills development across the whole research team.

Before this project, the academic partners were not known to the non-academic stakeholders, and the initial engagement and trust-building exercise required concerted effort. During project implementation, the research team invited all partners to contribute their ideas in annual facilitated Stakeholder Workshops and regular newsletters.

One goal expected to be achieved in early 2021 is the creation of an on-line interface that stakeholders and other interested parties can use, allowing them to plug in different variables and visualise expected outcomes for different parts of the system.

\section{Lessons learned:}

- Decisions take longer than when working within a single discipline, a factor that briefly slowed project initiation. Building good relationships has been essential. Monthly meetings with clear accessible minutes and actions circulated afterwards keep all partners up-to-date.

- Applying to a dedicated transdisciplinary funding programme was a very positive process and has ultimately enabled a complex challenge to be tackled with the full range of disciplines required.

Policy implications: The research environment and infrastructure can be adapted to support and encourage TDR. In this case, the University of Leeds was well-placed to host the project having invested EUR 43M in infrastructure that provides seamless access to the expertise, talent and facilities available at the institution. 


\section{Sociotechnical Systems to Enable Smart and Connected Energy-Aware Residential Communities (SCC-IRG Track 1)}

- Main Institutions: Purdue University.

- Disciplines involved: Civil/Mechanical engineering, Communication, School of Management, political science, Computer and Information Technology, Technology Leadership \& Innovation.

- Societal partners: The Indiana Housing and Community Development Agency (IHCDA) and housing developers

- Funding and timing: 3.16M EUR (2015-). Main funding from the National Science Foundation.

Summary: This project aims to develop a new paradigm for smart and connected residential communities that engage inhabitants in understanding and reducing their home energy use while increasing their environmental awareness, responsiveness to collective goals, and improving their quality of life. The research has provided new insights into how individuals, groups, and residential communities make decisions related to their home energy consumption. Based on this knowledge, the project developed feedback mechanisms integrated into user-interactive smart devices to enable optimal energy management. The Indiana Housing and Community Development Agency (IHCDA), several industry stakeholders and community residents have been engaged throughout the lifetime of the project. Smart and connected (S\&C) technology has been implemented in multiple residential communities that cover a range of demographics, locations, and construction and are used as research test-beds.

Engagement activities with the IHCDA and community developers began in 2015 through the "Moving Forward" program, which uses Rental Housing Tax Credits (RHTC) from the federal government to fund the development of energy-efficient, affordable housing and transportation. The communities set ambitious goals for energy use, ranging from $30 \%$ reduction to net-zero energy. Metrics for success includes the percentage of residents who are satisfied with their technology and the extent of reduction in energy use.

The interdisciplinary Purdue team works closely with housing developers - the frequency of interaction varies from every day to every two weeks depending on the project phase. A project leadership team with participants from housing developers, IHCDA and Purdue meet once per month.

The key challenge has been the need to train students who can work across disciplines. Their strong partnership with IHCDA and housing developers has been the cornerstone for their success. Initially, the team invested a lot of time in the project without any dedicated funding before they were eventually awarded an NSF grant.

\section{Lessons learned:}

- Integration of the work with the implementation of new housing policies (e.g., RHTC) allowed the team to test and evaluate their technologies in residential houses.

- Agreeing ambitious and measurable goals was important for commitment from all stakeholders.

Policy implications: Research funders can provide 'exploratory' support for researchers to build partnerships with stakeholders before they apply for larger project grants. 


\section{Smart Community Policing}

- Main Institutions: Dongguk University

- Disciplines involved: Mechanical engineering; virtual reality (VR); artificial intelligence (AI); big data; police studies; forensic science; law studies; robotics.

- Societal partners: The law enforcement sector (e.g., Korea National Police Agency)

- Funding and timing: 7.2M EUR (2018-2025). Main funding from Korean National Research Foundation.

Summary: A Convergence Research Centre (CRC) has been established under the auspices of the Korean National Research Foundation, with an expected duration of 7 years. The Centre aims to modernise forensic science, diminish crime rates and strengthen societal security. Multidimensional analysis of criminal data to extract underlying determinants of crimes can lead to the illumination of patterns of criminal behaviour and context. This can inform the development of criminal forecast algorithms and thus to reductions in gender-related crimes, domestic violence and child abuse. This project will also identify characteristics of high-risk groups and crime hotspots. It will collect anthropometric data on criminals and thus aims to increase the clearance rate for unsolved crime files.

The project is being conducted by three teams. The first applies VR and AI to criminology. VR reconstruction of crime scenes may contribute to investigations of violent crimes, and bolster education on techniques for crime scene reconstruction and physical simulation, prediction and 3D visualisation of crime situations. The second group is developing technology to facilitate law enforcement, e.g. a robot to assist police investigators' surveillance robots and databases for forensic ontological and anthropological data in Korea. The third group will develop a big data platform for smart policing, using data collected both on- and offline, including information from police investigations and provided by citizens. Professors and students from different university departments are part of these three interdisciplinary teams.

The main non-academic stakeholders are from the law-enforcement sector but the plan is to run civic education programs and develop prevention and response scenarios for child abduction and violent crimes. The aim is to also construct a service system to support local government offices, investigative offices, non-government organisations and citizens. The trans-disciplinary, co-design and co-production, aspects of such a system will be important but have not yet been fully worked out.

\section{Lessons learned:}

- The initial focus of the Smart Community Policing Centre has been on the potential of converging technologies to improve policing but as public service considerations become more prevalent then trans-disciplinary research approaches are likely to be required.

Policy implications: There is a need for TDR research in relation to the design and deployment of powerful digital technologies in the service of the public. 
25. Smart Grids [https://www.nwo-mvi.nl/project/developing-and-implementing-smart-gridsindia]

- Main Institutions: Eindhoven University of Technology.

- Disciplines involved: Science and technology studies; human geography; ethics; SSH; electrical engineering, industrial design.

- Societal partners: Private companies (especially start-ups/small- and medium-sized enterprises); local citizens.

- Funding and timing: EUR 350K (2016-2020) plus in-kind and cash support from companies. Main funding from Dutch Research Council's Platform for Responsible Innovation (NWO-MVI).

Summary: The bottleneck for the success of smart grids for electricity distribution is the difficulty of embedding the technology in a way that is both socially accepted and ethically acceptable. Empirically grounded insights and an ethical focus on the most vulnerable stakeholders are needed to address this challenge. Informed by such considerations, this project is guided by the following overarching research question: How can smart grids be successfully developed and implemented in rural India?

The project closely monitors and informs the development and implementation of smart grids in Indian villages. Through an interactive process, it defines, develops and tests prototypes that enable a "smart" exchange of electricity in Indian villages. These "local insights" are related to a broader perspective which offers insights about the wider societal embedding of smart grids and possibilities of upscaling.

One key to a successful project design was to consistently aim for the best quality in terms of solutions. For example, the team pitched products from its commercial project partner to various experts in India, soliciting feedback and suggestions for improvement. Visits to proposed target sites were important and it was important also to engage closely with partners, developing personal contacts and trusted relationships. At the level of potential users, it was important for this project to recognise that women play a central role in energy access issues in Indian villages and so their perspectives were critical. The company partner in India had women as their main experts for energy access to villages.

The transdisciplinary approach offered a holistic view of smart grids and real-life impacts through the design, delivery and testing of prototypes. For example, the use of kerosene lamps subsidised in India and solar lamps will not sell as long as kerosene lamps are cheaper to use and available. Similarly, the arrival of the main electricity grid during the course of the project had implications for product-design. Through this project, the company partner learned about the scale and potential impact of these contextual issues, which affect the development of a viable business model for its technology.

\section{Lessons learned:}

- Transdisciplinary projects must engage people (academic and non-academic) who are capable and willing of engage beyond disciplinary siloes. In parallel, researchers should be more reflective about the project objectives and their own roles.

- Private companies, particularly SMEs, have short-term commercial imperatives and objectives that can make it difficult for them to dedicate resources and expertise to TD research projects.

- Gender is an important consideration when considering which actors to engage, and how, in TDR projects

Policy implications: Funding may be required to support the full engagement of non-academic partners in TDR projects and such funding can be difficult to secure. 


\section{Strategic University Network to Revolutionise Indian Solar Energy (SUNRISE) [http://www.sunrisenetwork.org/]}

- Main Institutions: Swansea University

- Disciplines involved: Materials Engineering

- Societal partners: Tata Group; Tata Institute of Social Sciences; Government of Maharashtra.

- Funding and timing: 7.5M EUR (2017-2021). Main funding from Global Challenges Research Fund (GCRF).

Summary: This project's primary objective is to ensure access to affordable, reliable, sustainable and modern energy for all. Sunrise is a joint UK-India project to develop low-cost, buildingintegrated solar technologies and deploy them in rural India. Led by Swansea University, the network unites 12 leading universities and several industrial collaborators from the UK and India in an equitable research collaboration. This international network will work to develop and implement a minimum of five solar-powered building demonstrators in rural India.

The project was funded via an EPSRC (UK) grant under the "Growing Research Capability Call" as part of the UK Global Challenges Research Fund (GCRF). It had precedents in previous projects and many of the academic partners had already worked with each other, although new, academic and non-academic partners were also engaged. Swansea University provided pump-priming funds to support initial pilot work and other resources were also leveraged to complement the GCRF resources and, for example, support PhD students or early career researcher workshops.

This project is innovative in involving a very broad range of academic and non-academic groups from photo-physicists and chemists through to the user communities in Indian villages. Whilst the programme is Engineering-led, the core team involved experts from Social Sciences with knowledge and experience of working with Indian communities and subsequently expanded to include Humanities specialists exploring the relationship between energy systems and gendered household practices. A strategy for community development was built at the outset and all project partners were involved in co-designing the work plan.

An Executive Management Team (EMT) reports to an Advisory Board (AB). The breadth of expertise on the $\mathrm{AB}$, which is chaired by a senior industrialist and champion of sustainable development generates independent advice and ensures impartiality with no vested interests. Ethical considerations are deeply ingrained in the project and the research partnership.

The research team found that shifting from laboratory work to direct engagement with users completely changed their framework for understanding and has been invaluable in terms of how they will shape and create future projects. Medium-term impacts are expected to be seen in India, but longer-term potential exists for similar efforts across the Global South

\section{Lessons learned:}

- The biggest challenge in TDR is making initial connections with new disciplines that have no prior experience of inter- or trans-disciplinary working. The most important characteristic of a successful transdisciplinary collaboration is having a network of previously-established trusted contacts that can be expanded upon as necessary.

Policy implications: Successful TDR teams and networks need to be valued and nurtured as a basis for future TDR and capacity building. Sandpit schemes can provide opportunities for establishing new connections across a range of disciplines and for exchange of ideas to seed new TDR. 


\section{Transdisciplinary Research Intervention Anchored in Luxembourg (TRIAL)} [http://www.trial-lux.be/fr/projet]

- Main Institutions: Université de Liège and Université catholique de Louvain

- Disciplines involved: Social science; philosophy; facilitation.

- Societal partners: Private sector; public sector; community/public representatives; citizens.

- Funding and timing: EUR 500K (2017-2021). Main funding from the Fund for Strategic Fundamental Research (Associated Fund of the F.R.S.-FNRS) - Walloon Institute for Sustainable Development (FRFS-WISD).

Summary: This project aims to develop a new method to bring together academic researchers, citizens and the other stakeholders to co-create environmental knowledge on issues facing the province of Luxembourg in Belgium. Through experimentation and evaluation of the implementation of an eco-citizen institute, the project expects to produce transformative knowledge to inform local solutions. To be successful and sustainable, the knowledge production process must incorporate non-academic perspectives and inputs that relate to the desired transformation.

While identifying research themes, the team held a citizen forum to gauge stakeholder opinions and identify their priorities. This was open to anyone with a link to the territory of Luxembourg with the research team ensuring that diversity was respected. The citizen's forum was asked to select from 3 potential issues following a discussion of potential benefits and risks for each of these. They eventually settled on a framing issue: sustainable and integrated management of the forest of Saint-Michel Freyr.

During the second phase, the team is collaborating with the private partner contracted by the Walloon Region to manage the forest of Saint-Michel Freyr. The collaboration aims to co-create a master plan for the sustainable management and exploitation of the forest with citizens and territorial actors. The purposes and interests of the partners and the researchers are different and data is required that will respond to different needs that do not always reflect the primary interests of the data collectors/controllers. This requires considerable negotiation.

\section{Lessons learned:}

- Without a transdisciplinary approach, it would be impossible to construct a framework based on the interacting dynamics of the territory and relevant actors.

- It is critical to understand the cultural habits and power ratios of residents, stakeholders, and authorities from a specific region in order to build trusted relationships, but this takes time.

- The time taken and resources required for problem definition and co-design processes is easy to underestimate and funding is necessary for some stakeholders.

Policy implications: Dedicated support is required for the problem definition and co-design phase of TDR projects. Research funders should make structural funding available to support partnerships between academic researchers and non-academic stakeholders from industry, public sector, and civil society. 


\section{Urban ecology meets architecture and urban planning}

- Main Institutions: University of Applied Sciences Eastern Switzerland; HSR Rapperswil; ETH Zurich.

- Disciplines involved: Econolocal genetics; conservation genetics; community ecology; urban ecology; biogeography; urban planning; landscape architecture; art; science communication; environmental psychology; cultural study; environmental humanity.

- Societal partners: Urban planning, green space management, and biodiversity conservation units of public city administrations; museum; private horticulture industry; citizens.

- Funding and timing: 850K EUR (2016-2021). Main funding from private philanthropy (Mercator Foundation), University of Applied Sciences Eastern Switzerland, HSR Rapperswil and ETH Zurich.

Summary: Cities are considered hotspots of biodiversity and urban ecosystem services are essential for sustainable and healthy cities. This project assesses strategies to promote biodiversity and ecosystem services in cities by integrating ecological research with research and practice in urban planning and design, and by engaging with the public through an arts-science project. The main goal was to develop evidence-based tools for urban planning that are adopted by practitioners. Thus, collaboration among practitioners, applied researchers and scientists from urban planning and ecology was essential. A secondary TDR goal was to embrace a paradigm shift in how we think about and values nature in cities - this underlay the arts-science collaboration and the citizen science approach

The primary base for the project is an urbanism and landscape architecture research institute within a university of applied sciences. Transdisciplinarity is the default research mode, with professors rooted in 12 different disciplines (architecture, landscape architecture, urban planning, history of landscape architecture, landscape planning, geography, horticulture, environmental engineering, digital building, ecology, environmental sciences) working closely together. ETH Zurich, which is world-leading research University, is a partner in the project with a specific interest in urban ecology and how basic ecology can contribute to support conservation of urban biodiversity. The Swiss network of environmental humanities is the $3^{\text {rd }}$ academic partner, with an interest in public understanding and engagement in grand challenges, such as biodiversity loss. One of the major challenges was developing a common conceptual understanding and terminology between urban ecology and urban planning at the outset. Once this had been achieved, each of these 3 partners led a specific research theme. The principle investigator is jointly affiliated to both the main institutions and has worked for several years with the third partner and so he provides the bridge between them.

\section{Lessons learned:}

- Different institutional settings present different advantages and disadvantages for TDR:

- Within Universities of applied Science, co-production is straightforward, as regular interactions between research and practice are common; some professors still maintain active practices and some practitioners are lecturers (e.g. in design studios). However, time and resources for (non-applied) research is very limited

- Within research universities, collaborating across disciplines and engaging with external stakeholders can be more challenging and the evaluation criteria focus on scientific publications. However, research is part of an academic's role and there is ready access to infrastructure and resources to conduct research.

Policy implications: There can be considerable considerable added-value in combining expertise from different types of institutions that do TDR research, in this case Universities of Applied Science and traditional Research Universities. 


\section{Concluding comments}

As described in the first part of this report and reiterated in individual case studies, Governments, research agencies, research institutions and international bodies all have a role to play in designing and implementing effective policy initiatives to promote TDR. Detailed recommendations and suggested actions, in this regard, are listed at the start of this report and will not be fully repeated here. However, a short summary of the roles for different actors is given below.

Governments need to recognise and promote transdisciplinary research, as an essential complement to other more traditional research approaches, in addressing complex societal challenges. Governments have a critical role to play in establishing the overall framework that enables and supports effective TDR.

Research funding agencies have a critical role to play by directly supporting and incentivising TDR research. This affects both prioritisation of research areas and changes to funding processes, including funding criteria, peer review and evaluation.

Universities and Public Research Institutions (PRIs) are the principle organisations through which TDR is carried out and their long-term strategic commitment and support is essential if TDR is to be expanded to the scale that is necessary to address complex societal challenges. This has implications for education and training, as well as research. It also cuts across the so-called $3^{\text {rd }}$ mission activities (societal engagement and innovation) of Universities and PRIs.

The academic community has a major influence on science policy development and the definition of research strategies and priorities. It is responsible for conducting peer review and evaluation processes and often has a strong voice in how these are designed and conducted. Universities and PRIs tend to have considerable autonomy and are rightly responsive to their academic employees. Thus, whilst policy-makers and other actors can provide mandates and incentives for TDR, their impact will be limited without the support of the academic community and its representative associations.

Intergovernmental organisations can enable TDR. One of the major policy drivers for more TDR is the UN Sustainable Development Goals. Inherent in these goals is the recognition that no single country can fully address them on its own and there is a need for more effective international cooperation and exchange. Whilst the UN and other international bodies, including the OECD do not have the resources or the authority to implement TDR at the scale required to address societal challenges, these international bodies can play an important role in building consensus and catalysing action.

In addition to these five groups of actors, who have the major responsibility for promoting and enabling TDR within scientific research systems, there are a number of other stakeholders that need to embrace TDR if we are to effectively address that complex challenges that society is currently confronted with. Principle among these are:

- The private sector has enormous intellectual, technological and financial resources as well as valuable data and information, all of which can be leveraged in TDR.

- Non-governmental organisations (NGOs) represent different societal interests and as such they can make a very valuable contribution to many TDR activities.

Addressing complex societal challenges is a shared responsibility that requires new knowledge, new technologies and changes in society. Science has a central role to play in informing the transformations that are required to ensure sustainable and prosperous futures. In order to achieve this, a paradigm shift is required and transdisciplinary research 
needs to be actively promoted and supported, as a natural complement to traditional research approaches. This requires changes not only within science systems but also support and engagement from other sectors of society. Policy-makers have a critical role to play in developing the framework that lowers the existing barriers to TDR and incentivises engagement by all actors. 


\section{Notes}

${ }^{1}$ United Nations Sustainable Development Goals, 2015.

${ }^{2}$ German philosopher E.Husserl introduced the term "Lifeworld (German:Lebenswelt)" to describe this.

${ }^{3}$ Ibid., paraphrasing Wilhelm Windelband's inaugural address as rector of Strassburg University, 1894.

${ }^{4}$ Each case study describes a project that integrates natural and SSH academic components and actors from more than one non-academic stakeholder domain. For example, a project might include hydrology, psychology, community representatives and local government.

${ }^{5}$ See for example www.transdisciplinarity.ch.

${ }^{6}$ Introductory phrases, in italics, reflect insights from case study reports that were prepared by expert group members who conducted interviews. They are extracts from these case notes and are not verbatim quotations.

${ }^{7}$ A freely available Massive Open Online Course (MOOC) on transdisciplinary research is available through the Swiss, Academies of Sciences at https://www.futurelearn.com/courses/partnering-for-change-linkresearch-to-societal-needs. 


\section{References}

Apostel, L. et al. (eds.) (1972), Towards Interdisciplinarity and Transdisciplinarity in Education and Innovation, OECD Publications Center.

Arnstein, S. (1969), "A Ladder Of Citizen Participation”, Journal of the American Institute of Planners, Vol. 35/4, pp. 216-224, http://dx.doi.org/10.1080/01944366908977225.

EC/OECD (2020), STIP Compass: International Database on Science, Technology and Innovation Policy (STIP), https://stip.oecd.org (accessed on 14 May 2020).

Enengel, B. et al. (2012), "Co-production of knowledge in transdisciplinary doctoral theses on landscape development-An analysis of actor roles and knowledge types in different research phases", Landscape and Urban Planning, Vol. 105/1-2, pp. 106-117, http://dx.doi.org/10.1016/j.landurbplan.2011.12.004.

Gredig, D. (2011), "From research to practice: Research-based Intervention Development in social work: developing practice through cooperative knowledge production”, European Journal of Social Work, Vol. 14/1, pp. 53-70, http://dx.doi.org/10.1080/13691457.2010.516624.

Hadorn, G. et al. (eds.) (2008), Handbook of Transdisciplinary Research, Springer Netherlands, Dordrecht, http://dx.doi.org/10.1007/978-1-4020-6699-3.

Hernandez Montoya, A. (ed.) (2017), "Interdisciplinary Collaboration between Natural and Social Sciences - Status and Trends Exemplified in Groundwater Research”, PLOS ONE, Vol. 12/1, p. e0170754, http://dx.doi.org/10.1371/journal.pone.0170754.

Hulhoven, X. (n.d.), Develop a sustainable future for Brussels through a co-creation project, https://innoviris.brussels/co-creation (accessed on 27 May 2020).

Jahn, T., M. Bergmann and F. Keil (2012), "Transdisciplinarity: Between mainstreaming and marginalization”, Ecological Economics, Vol. 79, pp. 1-10, http://dx.doi.org/10.1016/j.ecolecon.2012.04.017.

Klein, J. (2008), "Evaluation of Interdisciplinary and Transdisciplinary Research", American Journal of Preventive Medicine, Vol. 35/2, pp. S116-S123, http://dx.doi.org/10.1016/j.amepre.2008.05.010.

Lang, D. et al. (2012), "Transdisciplinary research in sustainability science: practice, principles, and challenges", Sustainability Science, Vol. 7/S1, pp. 25-43, http://dx.doi.org/10.1007/s11625-011-0149-x.

Moser, S. (2016), "Can science on transformation transform science? Lessons from co-design", Current Opinion in Environmental Sustainability, Vol. 20, pp. 106-115, http://dx.doi.org/10.1016/j.cosust.2016.10.007.

Noah, W. and M. Jean (1980), Webster's New Twentieth Century Dictionary of the English Language, Unabridged, W. Collins. 
OECD (2017), “Open research agenda setting”, OECD Science, Technology and Industry

Pohl, C., P. Krütli and M. Stauffacher (2017), "Ten Reflective Steps for Rendering Research Societally Relevant", GAIA - Ecological Perspectives for Science and Society, Vol. 26/1, pp. 43-51, http://dx.doi.org/10.14512/gaia.26.1.10.

Pohl, C. et al. (2011), Questions to evaluate inter- and transdisciplinary research proposals, td-net for Transdisciplinary Research.

Roux, D. et al. (2010), "Framework for participative reflection on the accomplishment of transdisciplinary research programs", Environmental Science \& Policy, Vol. 13/8, pp. 733741, http://dx.doi.org/10.1016/j.envsci.2010.08.002.

Schneider, F. et al. (2019), "Research funding programmes aiming for societal transformations: Ten key stages”, Science and Public Policy, Vol. 46/3, pp. 463-478, http://dx.doi.org/10.1093/scipol/scy074.

Stauffacher, M. et al. (2008), "Analytic and Dynamic Approach to Collaboration: A Transdisciplinary Case Study on Sustainable Landscape Development in a Swiss Prealpine Region", Systemic Practice and Action Research, Vol. 21/6, pp. 409-422, http://dx.doi.org/10.1007/s11213-008-9107-7.

Swiss Academies of arts and sciences (n.d.), td-net Network for Transdisciplinary Research, http://www.transdisciplinarity.ch/en/td-net/Transdisziplinarit-t/Definitionen.html (accessed on 27 May 2020).

The World Commission on Environment and Development (1987), Report of the World Commission on Environment and Development - Our Common Future.

Tress, B., G. Tress and G. Fry (2006), "Defining concepts and the process of knowledge production in integrative research", in Tress, B. et al. (eds.), From Landscape Research to Landscape Planning: Aspects of Integration, Education and Application, Springer, Dordrecht.

Van Noorden, R. (2015), "Interdisciplinary research by the numbers", Nature, Vol. 525/7569, pp. 306-307, http://dx.doi.org/10.1038/525306a.

Wright Morton, L., S. Eigenbrode and T. Martin (2015), "Architectures of adaptive integration in large collaborative projects", Ecology and Society, Vol. 20/4, http://dx.doi.org/10.5751/es-07788-200405.

Zinsstag, J. et al. (2015), One Health: The Theory and Practice of Integrated Health Approaches, CABI. 


\section{ANNEXES}

Annex 1. GSF Expert Group Membership

\begin{tabular}{|c|c|c|}
\hline Country & Name & Affiliation \\
\hline Belgium & Audrey Segerie & Fonds de la Recherche Scientifique - FNRS \\
\hline Colombia & Tania Catalina Delgado & Ministry for Research and Culture (Colciencias) \\
\hline France & Patrick Criqui & CNRS and Université Grenoble Alpes \\
\hline Germany & Cornelia Reimoser & $\begin{array}{l}\text { Forschungskoordination Innovationsforschung, Vorstandsstab } \\
\text { Forschung } \\
\text { Zentrale der Fraunhofer-Gesellschaft }\end{array}$ \\
\hline Japan & Tateo Arimoto (co-chair) & $\begin{array}{l}\text { Professor at National Graduate Institute For Policy Studies } \\
\text { (GRIPS) and Principal Fellow, Center for Research and } \\
\text { Development Strategy, Japan Science and Technology Agency } \\
\text { (JST/CRDS) }\end{array}$ \\
\hline Japan & Kazuhito Oyamada & $\begin{array}{l}\text { Fellow, Center for Research and Development Strategy, Japan } \\
\text { Science and Technology Agency (JST/CRDS) }\end{array}$ \\
\hline Japan & Kazuhisa Yoshida & $\begin{array}{l}\text { Fellow, Center for Research and Development Strategy, Japan } \\
\text { Science and Technology Agency (JST/CRDS) }\end{array}$ \\
\hline Korea & Kiwoo Chun & Senior Researcher, National Research Foundation of Korea \\
\hline Korea & Soonkeon Nam & Dean, Office of Planning \& Coordination, Kyung Hee University \\
\hline Netherlands & Behnam Taebi & Delft University of Technology \\
\hline Norway & Lillian Baltzrud & $\begin{array}{l}\text { Senior Adviser, Department of University and University College } \\
\text { Policy, Research Council of Norway }\end{array}$ \\
\hline Switzerland & Jakob Zinsstag (co-chair) & $\begin{array}{l}\text { Deputy head, Department of Epidemiology and Public Health, } \\
\text { Swiss Tropical and Public Health Institute }\end{array}$ \\
\hline United Kingdom & Anne-Mette Olesen & $\begin{array}{l}\text { International Policy Manager, International Shared Capability, } \\
\text { UK Research and Innovation (UKRI) }\end{array}$ \\
\hline United Kingdom & Jo O’Leary & $\begin{array}{l}\text { Head of Unit, UKRI- Biotechnology and Biological Sciences } \\
\text { Research Council (BBSRC) }\end{array}$ \\
\hline United Kingdom & Riaz Bhunnoo & $\begin{array}{l}\text { Director of the Global Food Security Programme, UKRI- } \\
\text { Biotechnology and Biological Sciences Research Council } \\
\text { (BBSRC) }\end{array}$ \\
\hline United States & Dragana Brzakovic & National Science Foundation \\
\hline Consultant & José Siri & Wellcome Trust, Our Planet Our Health \\
\hline
\end{tabular}




\section{Annex 2. Case study questionnaire}

I. General project information [to be completed prior to interview]

1) Title

2) Years of operation

3) Total budget

4) Annual budget

5) Funding source(s)

6) Principal investigator

7) Principal investigator's discipline

8) Principal investigator's affiliation

9) Location(s) of research team

10) Study sites (i.e., cities/countries)

11) Scale of analysis (i.e., local/national/regional/global)

12) Primary objectives (i.e., what societal challenge is being addressed?)

13) Brief description

\section{Project design and structure}

1. Research themes:

a. How were research/working themes identified or selected?

b. What partners drove this process? Was there consultation with other actors?

c. Did research themes evolve during participatory engagement? Please describe.

2. Briefly describe the project leadership and management. How were decisions made with respect to:

a. Overall project direction and research questions.

b. Day-to-day project functioning.

3. Academic participants:

a. How were the principal/main investigators selected?

b. What disciplines were actively engaged in designing and implementing the project? What was the split between natural sciences and SSH?

c. What other disciplines, if any, contributed significantly to the project? Were any approached that did not eventually contribute and, if so, why?

d. How did the depth of engagement of different disciplines vary over time?

e. What processes, formal and informal, were in place to integrate across disciplines?

4. Non-academic participants (private sector, civic sector, community/public representatives, other)

a. How were non-academic partners selected?

b. Which non-academic participants, from which domains, were actively involved in designing and/or implementing the project?

c. What other participants, from which domains, contributed significantly to the project? Were any approached that did not eventually contribute and, if so, why?

d. How did the depth of engagement of non-academic partners vary over time? Were there moments when they were highly involved, and to what extent were they engaged/involved during intervening stretches?

e. What processes, formal and informal, were in place to integrate academic and non-academic perspectives and participants?

5. Existing relations and networks

a. Were there historical antecedents or pre-existing relationships that laid a foundation for the research team?

b. How was the transdisciplinary network built and what was new for this project?

c. To what extent were the various partners already familiar with each other?

6. Why did the project adopt a transdisciplinary approach? What were the motivating factors? 


\section{6 | ADDRESSING SOCIETAL CHALLENGES USING TRANSDISCIPLINARY RESEARCH}

7. Did non-academic processes (e.g., political, business or fiscal cycles) drive any aspects of the project design or timing?

8. Are any aspects of the project design novel or unique? Please briefly describe.

9. Was any particular attention given to ethical and/or equity issues, and, if so, how did this influence project design?

\section{Project outputs, monitoring and impact}

1) How was project performance monitored over different timeframes? Briefly describe any formal or informal monitoring mechanisms.

2) What were the main project outputs?

3) What were the expected project impacts? How are these being assessed?

4) Did the transdisciplinary approach adopted by the project offer any advantages or disadvantages compared with traditional approaches? Please describe.

5) Were any project outputs or impacts directly attributable to the adoption of a transdisciplinary approach?

6) Has consideration been given to the equitable distribution of benefits and/or potential unintended consequences arising from this project? Briefly describe any mechanisms to improve/ensure equity

\section{Implementation challenges}

1) What were the main challenges in implementing transdisciplinarity in this project with respect to each of the following issues? What steps were taken to address them?
a. Selection of appropriate methods
b. Selection of appropriate partners
c. Ensuring inclusion of diverse perspectives
d. Institutional arrangements and support (research environment)
e. Leadership, governance and/or management
f. Funding (including the project proposal review process)
g. Participation of academic staff from different disciplines (including publication expectations)
h. Participation of students and early career researchers (including employment expectations, career paths and incentives)
i. Communication between academia and non-academic partners
j. Cultural/language barriers
k. Data management and integration
1. International harmonization/trust building, if appropriate
m. Other obstacles (e.g., regulations or standards around data sharing)

2) What, in your view, is the most important challenge/obstacle to implementing transdisciplinary research? Please explain in detail

3) In your experience what are the most important characteristics of successful transdisciplinary research projects?

\section{Supportive actions}

1) What can actors in each of these domains do to help to resolve/mitigate the above challenges and promote transdisciplinary research?
a. Governments
b. Research funders
c. Universities/research institutions
d. International organizations (e.g., UN system) 


\section{Annex 3. Workshop on transdisciplinarity and sustainability research, 24 May 2019, Paris}

At: Ministry of Higher Education, Research and Innovation 25 rue de la Montagne Sainte Geneviève, 75005 Paris

\section{Aims of the workshop}

Following an overview of key conceptual and methodological issues, several different cases studies will be presented and for each of these the same four over-arching questions are to be addressed:

1. What are is the added value of using a transdisciplinary approach (aims and impact)?

2. What are the main obstacles and challenges to implementing transdisciplinary research?

3. What has been done (good practices) to address these obstacles/challenges?

4. What can policy makers (governments, research institutions, funders) do to promote transdisciplinary research?

\section{Workshop Agenda}

09h00 Opening session

Jacob Zinsstag, welcome from the GSF Expert Group co-chair

Bernard Larrouturou, Head of general directorate for Research and Innovation at French ministry of research

Carthage Smith, Senior Policy Analyst - Lead Co-ordinator, OECD Global Science Forum

09h15 Roland Scholz, Professor Emeritus of Environmental Systems Science at Eidgenössische Technische Hochschule (ETH Zürich)

Transdisciplinarity: evolution and limitations of the concept

10h15 Rémy Slama, Environmental Epidemiologist at Institut national de la santé et de la recherche médicale (Inserm)

Path of successive research projects/journey to inclusive transdisciplinary [30min $+30 \mathrm{~min}$ discussion]

11 h15 break

$11 \mathrm{~h} 30$ Anne-Sophie Stevance, Science Officer at International Science Council (ISC) and, Sandrine Paillard, Global Hub Director at Future Earth

Future Earth: challenges and lessons learned [30min+30min discussion]

12 h30 Lunch

13.45 Case study analysis framework - Jakob Zinsstag

14h Case study 1: One Health project [20min+40min discussion]

Ethiopia-Switzerland cooperative project for the improvement of health and wellbeing of communities

Kadra Osman Ali, Jigjiga University, Ethiopia

15h Case study 2: MontanAqua [20min+40min discussion]

Water management project in times of scarcity and climate change in Switzerland

Flurina Schneider, Centre for Development and Environment, University of Berne

$16 h$ break

16h30 Case study 3: APV-RESOLA [20min+40min discussion]

Food-energy nexus project for rural development in Germany

Christine Rösch, Head of Sustainability and Environment, Institute for Technology Assessment and Systems Analysis, Karlsruhe Institute of Technology

$17 \mathrm{~h} 30$ Conclusions

Patrick Monfray, deputy head of service of research and innovation strategy

Jakob Zinsstag, GSF Expert Group co-chair

Tateo Arimoto, GSF Expert Group co-chair

17h45 End of workshop

Participants: 50 people from academia, French Ministry for Research and funding agencies and OECD. 


\section{8}

ADDRESSING SOCIETAL CHALLENGES USING TRANSDISCIPLINARY RESEARCH

\section{Annex 4. Workshop on Transdisciplinary Research, 5 December 2019, Tokyo}

\section{Organizers:}

Ministry of Education, Culture, Sports, Science and Technology, Japan (MEXT)

Center for Research and Development Strategy, Japan Science and Technology Agency (JST-CRDS)

OECD Global Science Forum (GSF)

\section{Aim of the workshop:}

To discuss the following issues in the context of specificTDR projects;
a. added value of using a TDR approach
b. how to promote collaboration among different disciplines
c. how to involve various stakeholders
d. evaluation of impact

\section{Workshop Agenda:}

10:00 Opening remarks

Tateo Arimoto, co-chair of OECD/GSF Transdisciplinary Research (TDR) project

MEXT and Cabinet Office, Japan

Carthage Smith, $O E C D / G S F$

10:20 Key note (30min +30 min discussion)

Hiroko Akiyama, Institute of Gerontology, University of Tokyo, Japan

11:20 Case study 1 (30min $+20 \mathrm{~min}$ discussion)

Mobility Innovation Center, COI (The Center of Innovation) Program, Nagoya University, Japan

Takayuki Morikawa, Research Leader, Mobility Innovation Center; Professor, Institutes of Innovation for

Future Society, Nagoya University

12:10 Lunch (70min)

13:20 Case study 2 (30min +20 min discussion)

International Research Institute of Disaster Science (IRIDeS), Tohoku University, Japan

Fumihiko Imamura, Director, IRIDeS, Tohoku University, Japan

14:10 Case study $3(30 \mathrm{~min}+20 \mathrm{~min}$ discussion $)$

Korean Case

Soonkeon Nam, Director, The Centre for Strategic Planning, Korea

15:00 Break

15:20 Case study 4 (30min $+40 \mathrm{~min}+20 \mathrm{~min}$ discussion)

Japan-ASEAN Science, Technology and Innovation Platform (JASTIP), Kyoto University, Japan, and its Collaborative Institution in Malaysia

Ryuichi Fukuhara, Programme Coordinator, JASTIP, Kyoto University, Japan

Hideaki Ohgaki, Professor, Kyoto University, Japan

Che Hang Seng, Senior Lecture, Um Power Energy Dedicated Advanced Centre (UMPEDAC), University of Malaya, Malaysia

16:50 General Discussion (30min)

17:20 Conclusion and closing remarks

Jakob Zinsstag, co-chair of OECD/GSF TDR project

Tateo Arimoto, co-chair of $O E C D / G S F T D R$ project

Participants: Approx. 50 people from MEXT, Cabinet Office, JST, OECD/GSF TDR EG members, etc. 


\section{Glossary}

Differences in definitions and terminology among different communities, including policymakers, can inhibit discourses on transdisciplinarity. Working definitions for some key terms, as adopted for this report, are given here (Tress, Tress and Fry, 2006 [23]; Moser, 2016[24]; Noah and Jean, 1980[25]).

\begin{tabular}{|c|c|}
\hline $\begin{array}{l}\text { Disciplinary } \\
\text { research }\end{array}$ & $\begin{array}{l}\text { Research that takes place within the bounds of a single, currently recognised academic } \\
\text { discipline. }\end{array}$ \\
\hline $\begin{array}{l}\text { Interdisciplinary } \\
\text { research }\end{array}$ & $\begin{array}{l}\text { Research that involves several unrelated academic disciplines in a way that forces them to } \\
\text { cross subject boundaries to create new knowledge and theory in achieving a common goal. } \\
\text { Integration of natural sciences with social sciences and humanities (SSH) is particularly } \\
\text { relevant to addressing complex societal challenges, including those related to human- } \\
\text { environmental systems (HES), but poses substantial challenges. }\end{array}$ \\
\hline $\begin{array}{l}\text { Multidisciplinary } \\
\text { research (also } \\
\text { pluridisciplinary } \\
\text { research) }\end{array}$ & $\begin{array}{l}\text { Research that involves several different academic disciplines working in parallel on one } \\
\text { theme or problem, often with a common goal, yet following their individual disciplinary } \\
\text { precepts and ways of working. Participants exchange knowledge, but do not aim to cross } \\
\text { subject boundaries to create new, integrated knowledge and theory. This lack of } \\
\text { integration may make it difficult to satisfactorily resolve complex societal problems. }\end{array}$ \\
\hline $\begin{array}{l}\text { Participatory } \\
\text { research }\end{array}$ & $\begin{array}{l}\text { Research that brings together academic and non-academic partners to exchange } \\
\text { knowledge without necessarily integrating that knowledge. Participatory research is } \\
\text { sometimes used as an umbrella term that encompasses numerous methods that involve } \\
\text { non-academic participants to different degrees in research processes. }\end{array}$ \\
\hline $\begin{array}{l}\text { Transdisciplinary } \\
\text { research }\end{array}$ & $\begin{array}{l}\text { Research that integrates both academic researchers from unrelated disciplines - } \\
\text { including natural and social sciences- and non-academic participants to achieve a } \\
\text { common goal involving the creation of new knowledge. TDR is necessarily } \\
\text { interdisciplinary. In drawing on non-scientific knowledge domains such as local and } \\
\text { traditional knowledge, and cultural norms and values, it aims to supplement and } \\
\text { transform scientific insights for the good of society. }\end{array}$ \\
\hline Co-design & $\begin{array}{l}\text { First phase of a research process, in which researchers and non-academic partners jointly } \\
\text { develop a research project and define research questions that meet their collective } \\
\text { interests and needs. }\end{array}$ \\
\hline Co-production & $\begin{array}{l}\text { A collaborative model that includes stakeholders in the knowledge production phase of } \\
\text { the research process, e.g., engagement of patients in health research. }\end{array}$ \\
\hline Science & $\begin{array}{l}\text { Systematised knowledge derived from observation, study, and experimentation carried on } \\
\text { in order to determine the nature or principles of what is being studied; a branch of } \\
\text { knowledge or study, especially one concerned with establishing and systematising facts, } \\
\text { principles, and methods, as by experiments and hypotheses. Sometimes "Science" is used } \\
\text { to denote natural sciences, as opposed to Social Sciences and Humanities (SSH); however, } \\
\text { in its broadest interpretation it encompasses all disciplines of academic knowledge and } \\
\text { both quantitative and qualitative methods. }\end{array}$ \\
\hline Discipline & $\begin{array}{l}\text { Branch of knowledge or learning. Practitioners of a given discipline generally share } \\
\text { characteristic background knowledge, objects of analysis, terminology, analytic } \\
\text { methodologies, and mechanisms for training, collaboration and knowledge exchange. }\end{array}$ \\
\hline Natural science & $\begin{array}{l}\text { Systematised knowledge of nature and the physical world, including zoology, botany, } \\
\text { chemistry, physics, geology, etc., or any of these branches of knowledge. }\end{array}$ \\
\hline Social science & $\begin{array}{l}\text { quantitative data about } \\
\text {, communities, races etc., or }\end{array}$ \\
\hline
\end{tabular}




\begin{tabular}{l|l}
\hline Humanities & $\begin{array}{l}\text { any of several branches of knowledge, as history, economics, civics, etc., dealing with the } \\
\text { structure of society and the activity of its members. }\end{array}$ \\
\hline Stakeholder & $\begin{array}{l}\text { Academic disciplines that study aspects of human society and culture. They include } \\
\text { literature, philosophy and history. }\end{array}$ \\
\hline $\begin{array}{l}\text { Stakeholder } \\
\text { domain }\end{array}$ & $\begin{array}{l}\text { A person, group or organisation with an interest in a particular project } \\
\text { Stakeholders within a particular domain often have similar priorities, incentives and ways } \\
\text { of addressing problems. Four stakeholder domains were defined for this report: public } \\
\text { sector (e.g., government and public authorities); private sector (e.g., business and } \\
\text { industry); civic sector (e.g., NGOs, charities); and/or direct representatives of } \\
\text { communities (e.g., lay persons) }\end{array}$ \\
\hline Epistemology & $\begin{array}{l}\text { The study or a theory of the nature and grounds of knowledge especially with reference to } \\
\text { its limits and validity }\end{array}$ \\
\hline $\begin{array}{l}\text { Scientific } \\
\text { Paradigm }\end{array}$ & $\begin{array}{l}\text { A set of concepts, analytical tools and research methods that characterize the way a } \\
\text { discipline identifies and solves scientific problems (the paradigm of a chemist is different } \\
\text { to that of a physicist, and that of an economist different to that of a sociologist). In a } \\
\text { broader sense, a paradigm shift occurs when, a systemic change in these concepts-tools- } \\
\text { methods occurs in one or several disciplines. }\end{array}$ \\
\hline
\end{tabular}

